\title{
CUSTOMER-LED VERSUS MARKET-ORIENTED: AN INVESTIGATION OF THE LEAN STARTUP METHODOLOGY FRAMEWORK
}

by

Ismail Mohamed Jimale

\author{
A thesis \\ submitted to the Victoria University of Wellington \\ in fulfilment of the \\ requirements for the degree of \\ Master of Advanced Technology Enterprise
}

Victoria University of Wellington 


\section{Abstract}

Market-oriented approach to customer development has been strongly associated innovativeness and new product success. There is also evidence to suggest customer-led approach, or responding to explicit customer needs, impedes innovation. This thesis investigates whether the increasingly popular Lean Startup Methodology (LSM) favours customer-led or market-oriented approach to discovering and learning about customer needs.

The study was conducted using a participatory action research methodology. The LSM was used as a framework for investigating the commercial value of two researched projects originating from within Victoria University. The LSM was also applied to a third project founded by the Master of Advanced Technology Enterprise (MATE) team.

The LSM process is shown to assist in the discovery of both explicit and latent customer needs. However, which one the framework favours depends on whether the product or the market is the primary driver of the validation process. In one instance the entrepreneur is deliberately looking to discover a present market need in order to align it with a pre-defined solution, while the alternative is to study the market in order to identify an opportunity followed by the development of a specific solution. The latter is shown to support becoming market oriented.

The findings also suggest Domain Knowledge plays a vital role in establishing and maintaining market-oriented approach to customer development. Domain knowledge aids in understanding market data in order to extract novel and meaningful insights. Establishing close relationships with emerging customers and 'lead users' in a particular market is shown to be an effective method of compensating for a lack of domain knowledge. What's more, the presence of preconceived prototypes is shown to negatively impact on the entrepreneur's ability to approach customer development in a market-oriented manner.

By drawing on the MATE team's experiences, this thesis aims to provide practical lessons for individuals and teams that are looking to take a market-oriented approach to customer development. 


\section{Contents}

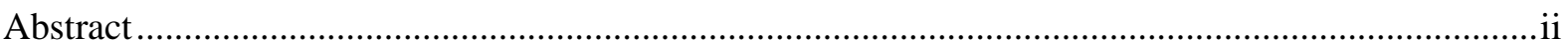

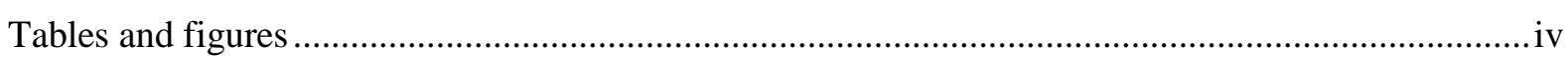

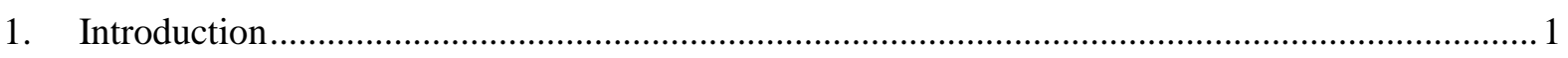

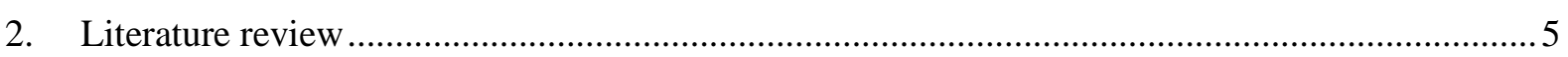

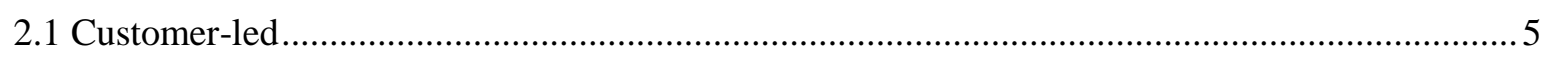

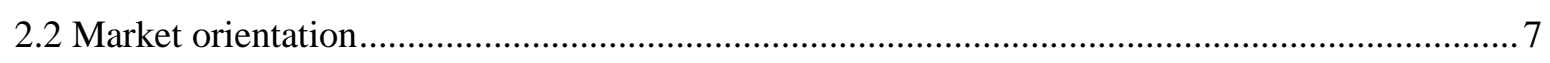

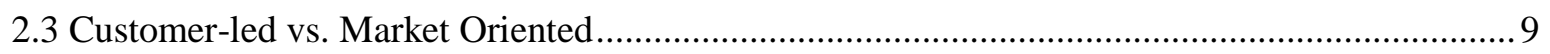

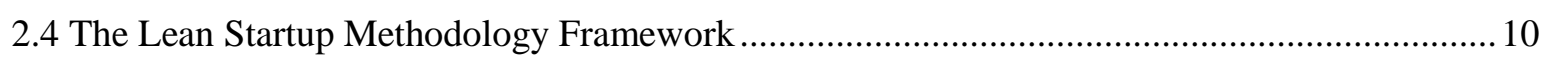

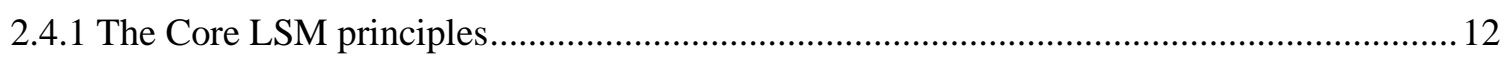

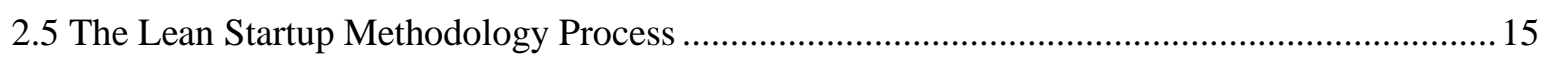

2.5.1 Phase 1: Market trends and competitive analysis .......................................................... 17

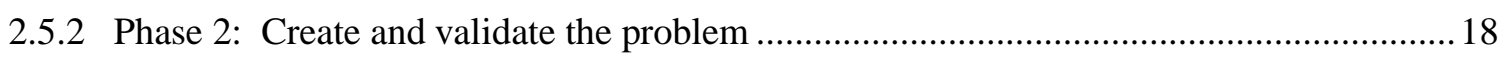

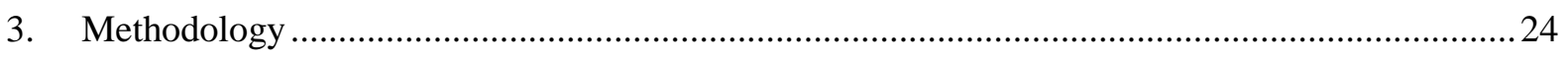

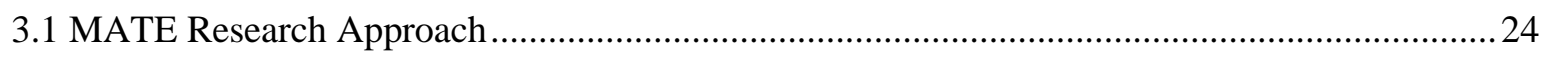

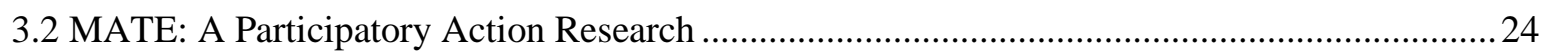

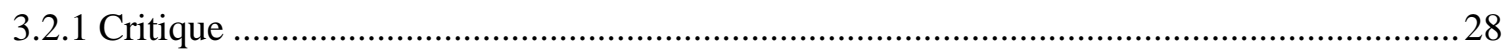

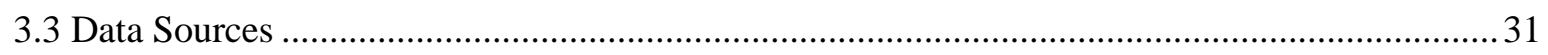

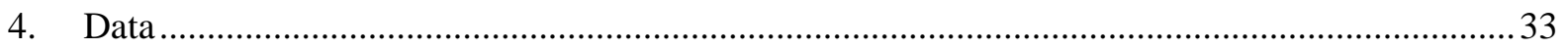

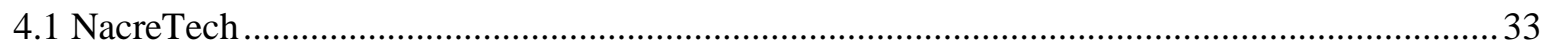

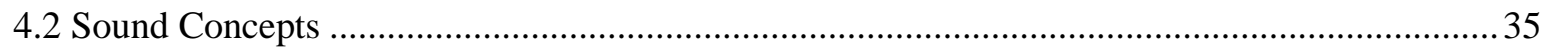

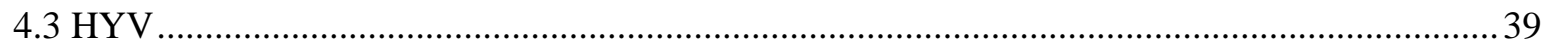

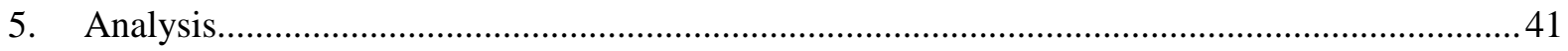

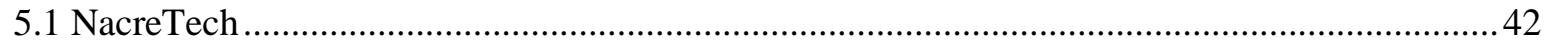

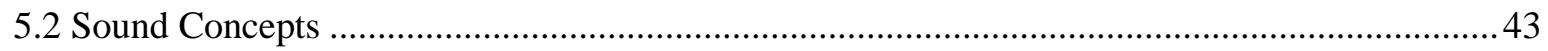

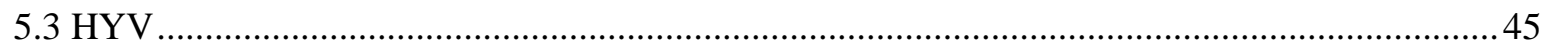

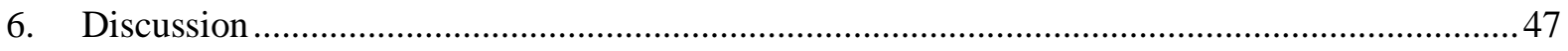

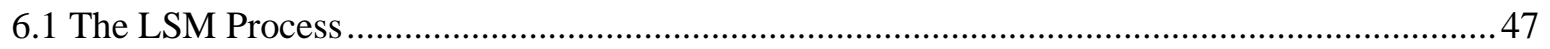

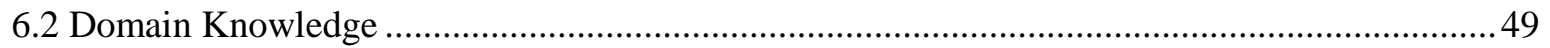

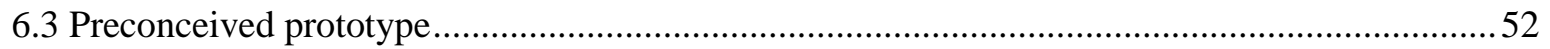

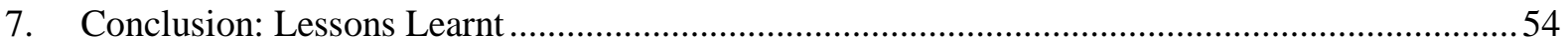

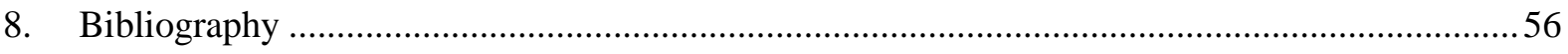

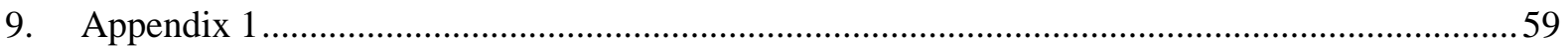




\section{Tables and figures}

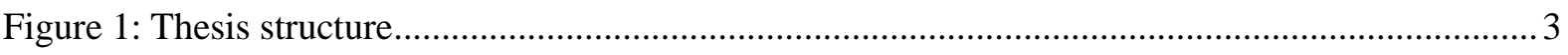

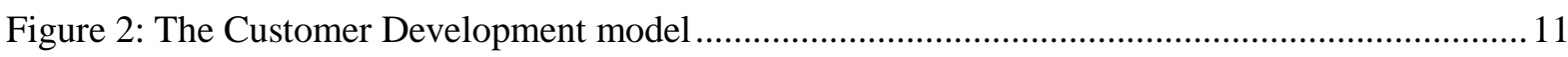

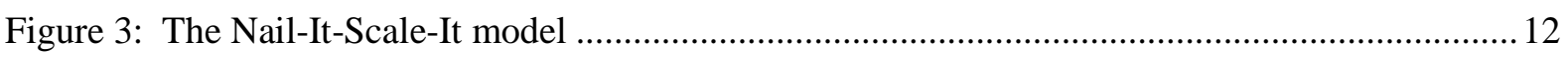

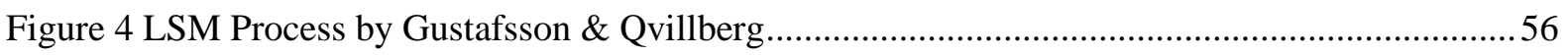

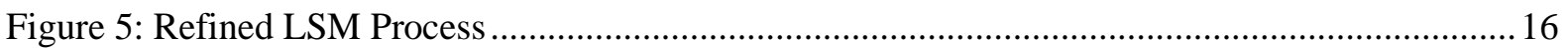

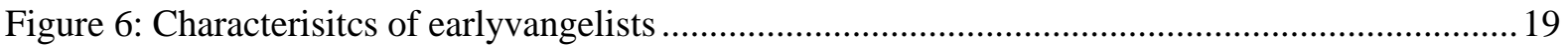

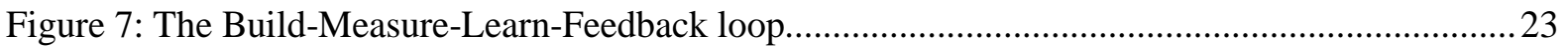

Figure 8: The cyclical similarities between MATE research process and O'Leary's cyclical research

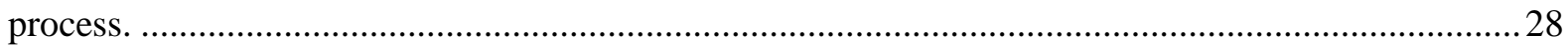

Figure 9: Summary of the extent to which each orientation was present during the course of the

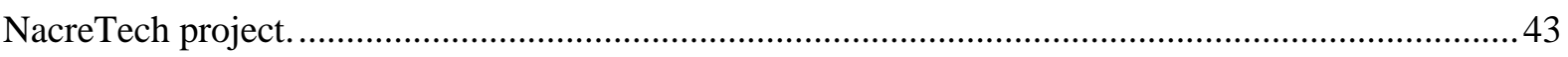

Figure 10: Summary of the extent to which each orientation was present during the course of the Sound Concepts project.

.44

Figure 11: Summary of the extent to which different approaches were present during the course of the HYV project. .45

Table 1: Characteristics of Customer-led and Market-orientedbusinesses ....... 41 


\section{Introduction}

The Lean Startup Methodology (LSM) has enjoyed huge amount of popularity amongst startup communities and new initiatives in large firms alike as a method for creating and managing new ventures. This breed of 'action' literature provides a strong focus on actual implementation and hands-on recommendations in order to mitigate the remarkably high rate of failure for new ventures (Hjalmarsson, 2010). At the heart of the LSM is the importance of discovering and learning customer needs in order to increase the adoption rate of new products or services. It utilises an iterative process where problem, product and customer hypotheses are formed and validated through different methods of primary market research techniques. Through this iterative process, the entrepreneur seeks to discover a unique value proposition which can be used to build scalable and repeatable business model (Blank, 2006).

The academic literature too emphasises the importance of understanding user requirements (B. Jaworski, Kohli, \& Sahay, 2000; Lukas \& Ferrell, 2000; Slater \& Narver, 1998). However, the appropriate role of the customer in innovation and new product development is one that continues to spur an on-going debate (Callahan \& Lasry, 2004). While some suggest customers are an important source of new product ideas (Hippel, Thomke, \& Sonnack, 1999; Hippel, 1986), others argue listening too closely to customers has inherent biases against the development of radically different new products (Christensen \& Bower, 1996).

Acknowledging this elusive role of the customer in innovation and new product development, Slater and Narver (1998) distinguish market orientation philosophy, from the less favourable, customer-led. Market-oriented businesses have a long term commitment to understanding customer needs - both expressed (e.g. present customers' articulation of existing needs) and latent (e.g. the discovery of unarticulated future needs). Customer-led businesses on the other hand, solely focus on satisfying the expressed needs of a known group of customers (Callahan \& Lasry, 2004). The implication of this distinction is that market orientation philosophy is strongly associated with innovativeness and new product success, while customer-led approach leads to incremental improvements on established market requirements and more imitative changes rather than radically different products or services (Atuahene-Gima et al., 2005; Narver, Slater, and MacLachlan, 2004). 
Which begs the question: If being market-oriented approach is strongly associated with innovativeness and new product success, while customer-led approach leads to incremental improvements, what is the outcome of using the highly customer-centric LSM process to discover and learn about customer needs?

This thesis examines the relationship between the LSM and being market-oriented or customer-led. The thesis draws on my experiences of following the LSM process to discover and learn about customer needs as part of the 2013 Master of Advanced Technology Enterprise (MATE) programme. MATE is a one year interdisciplinary programme that explores the relationship between research and commercialisation through the establishment of highly entrepreneurial teams of students. The primary objective of the programme is to explore the challenges of creating an advanced technology enterprise around promising research projects from within the university.

Over the course of twelve months, The MATE team took on three projects: NacreTech a synthetic composite material that closely resembles bone, Sound Concepts; a design-led acoustic product designed to reduce the effects of reverberation and improve acoustics in interior environments, $H Y V$; a versatile workspace solution that creates privacy in open plan offices. HYV was founded by my team in response to a market opportunity we discovered. The LSM process was followed to discover and learn about the needs of potential customers in different markets with an eventual goal of building a scalable and repeatable business model. Background information regarding the MATE programme as well as the projects is available in the MATE Group Report in Appendix 1.

The thesis draws on the data from the three projects we worked during the programme, coupled with my experiences as the Customer Development Lead for the MATE team. I used these experiences to draw meaningful insights in the following research objectives:

1) To investigate if the LSM favours customer-led or market-oriented approach in earlystage customer development?

2) What other factors influence whether the LSM process leads to market orientation or customer-led?

3) In practice, what is the likely outcome for someone who is using this method in earlystage venture? 
The following diagram provides a visual representation of the core research elements underpinning the thesis and how they all come together in achieving the research objectives set out above. The diagram also gives an indication of the logical structure for the thesis.

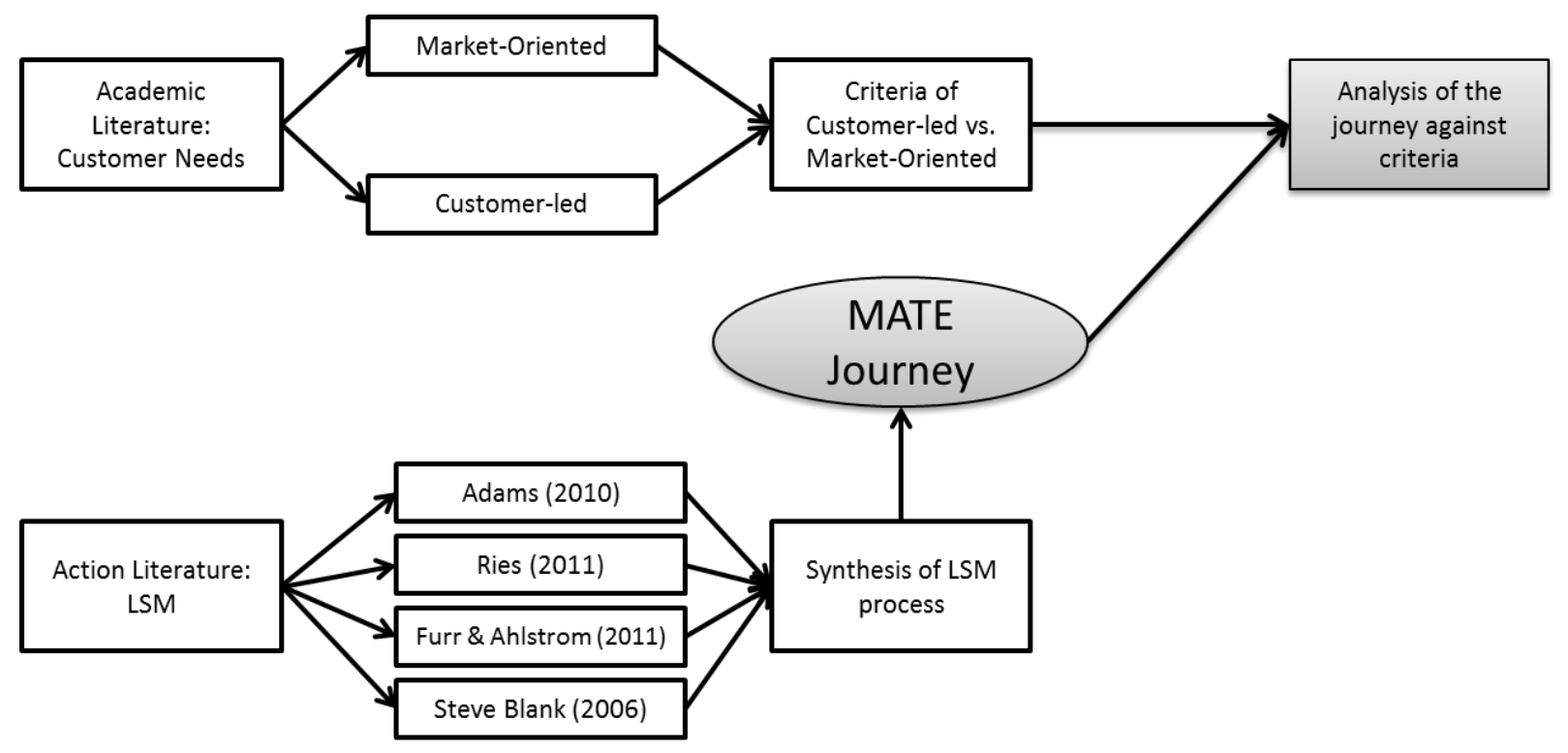

Figure 1: Thesis structure

As indicated by the upper branch of the diagram above, the two major academic views on customer development, (customer-led and market-oriented) are first discussed to arrive at clear distinction of what constitutes each philosophy. The second part of the literature review, indicated by the lower branch in the diagram, examines the LSM literature according to four of the most commonly cited authors. Using the common principles of the different authors, a single LSM framework is synthesised. These authors were significantly influential in my role as the customer development lead.

Second, the research approach and design is outlined in the methodology section. Here, I present my argument as to why the MATE research approach and design is valid under the core principles of Participatory Action Research according to O’Leary (2004).

Third, the MATE journey is summarised, highlighting our experience of following the LSM process and identifying periods when we might have become customer-led or market oriented. 
Fourth, in the analysis and discussion sections the academic criteria of what constitutes being customer-led or market-oriented are used to examine the team's experiences of following the LSM process. Finally the key lessons learnt are summarised in the conclusion section.

All in all, the thesis aims to effectively demonstrate the interplay between market-oriented and customer-led philosophies to understanding customer needs and the different factors that contribute to the adoption of one approach over the other. 


\section{Literature review}

This chapter offers an in-depth review of the different academic theories dealing with the appropriate role of the customer in innovation and new product development. The two major academic views discussed here are 'customer-led' and 'market oriented'. Although these two philosophies have historically been deemed to encompass the same thing, there is a breed of new literature which suggests that the two philosophies are in fact significantly different (Slater \& Narver, 1998). Given the main objective of this paper is to investigate whether the LSM process favours customer-led or market-oriented approach, the first part of this chapter is dedicated to establishing the premise for what constitutes customer-led and market orientation while the second part focuses on the LSM process according to four of the most widely cited authors.

\subsection{Customer-led}

The customer-led approach arguably stems from the marketing concept that a firm's very existence is defined by how well it can discover the needs and wants of customers in its chosen market, while also performing this more effectively and efficiently than others competing for the same target audience. Certainly much earlier than the modern marketing concept, Drucker (1954) argued that the defining purpose of a business is to create satisfied customers. Perhaps the customer-led approach reached its summits in the 1970s when there was a resurgence of interest in the marketing discipline. During this period, many markets were fast approaching maturity and competition among companies intensified. Resulting from the avalanche of changes in global economies, suddenly establishing and maintaining customer satisfaction was the forte of strategic business thinking. Hooley \& Lynch (1985) added their voice to this chorus by declaring "marketing excellence" as the differentiating key factor of best performing firms. This meant spending more resources on marketing in order to capture market shares in maturing markets.

The customer-led approach is understood to work well within known markets; where an organisation has a comprehensive understanding of their customers and the subsequent markets those customers fall into. Provided an organisation also has the appropriate processes and infrastructures for capturing and distilling customer information, the use of this 
information to inform further iterations (incremental improvements) and continuous innovation of existing products or services can improve the customer adoption rate (Eliashberg, Lilien, \& Rao, 1995).

There is polarised debate in regards to the role of a customer in development of very new products. Hippel (1986) highlights the importance of 'lead user' insights as a rich source of information into very new product development. He defines 'lead users' of products, process, or services on two fronts: they face needs that are more advanced than the general marketplace in the order of magnitude of months, if not years; they are positioned to significantly benefit from a solution that addresses those needs. Furthermore, because there is not an immediate solution on offer, 'lead users' tend to implement their own efforts in addressing their inconveniences. However, there are others (Ciccantelli \& Magidson, 1993; Neale \& Corkindale, 1998) who suggest being too close to customers or being "customerled" perhaps detracts from a firm's innovations and overall performance.

Christensen (1997) outlines the danger in becoming too attentive to the needs of customers in a firm's "value network". He explains an organisation that accumulates knowledge and skills for one product falls over when those skills and knowledge are irrelevant to a new product. Given these incumbent firms are unable to accommodate the requirements of a disruptive innovation; they eventually allow new entrants, who possess disruptive technologies, to take over their market. Hamel and Prahalad (1994) maintain that customers are "notoriously lacking in foresight". They are unable to imaginatively conceive what is possible, whereas the organisation is in a better position to do so. Hamel \& Prahalad (1994) suggest in order to successfully compete for the future; one must lead the public with new products instead of doing extensive market research into what customers need today. An organisation's customers today will not necessarily be tomorrow's, given that everything is subject to change in today's turbulent economic climate.

On the more extreme end of the spectrum, Martin (1995) affirms that firms should 'ignore their customers'. His argument adds on to the earlier work by Kohli and Jaworski (1990) who found that a customer-led approach detracts from an organisation's likelihood of developing a truly breakthrough innovation. 
In an attempt to bring things into perspective, Slater and Narver (1998) assert that the literature unintentionally confuses two different philosophies: market orientation, discussed in the next section and customer-led. The latter is characterised by a focus on understanding short-term, "expressed needs". By doing so, customer-led businesses utilise scientific marketing techniques such as surveys and focus groups to collect information that will enhance deeper understanding of how to better satisfy their existing customers. Coupled with techniques such as concept testing and conjoint analysis to guide product development, firms are then able to make incremental changes that influence purchasing decisions.

\subsection{Market orientation}

Since the early 1990s the concept of market orientation has received significant attention in terms of its meaning, measures and implementation. Some of the early work is dedicated to the meaning and measurements of market orientation (Kohli \& Jaworski, 1990; Narver \& Slater, 1990; Shapiro, 1988; Webster, 1988). The more recent literature, however, seems to focus on how to establish and maintain a market orientation (Day, 1994; Pelham \& Wilson, 1995), while the new context for studying market orientation gives special attention to the role of the customer in new product development (B. Jaworski, Kohli, \& Sahay, 2000; Lukas \& Ferrell, 2000; Slater \& Narver, 1998).

The first cornerstone of the market orientation construct arguably came about when Kohli and Jaworski (1990) articulated what they coined "the implementation of the marketing concept". They described it as a three dimensional construct consisting of the gathering of information about customers' present and future needs, the cross functional dissemination of such information within the organisation: and the organisational responsiveness to this information. Over the years, a number of writers have contributed to the conceptualisation of market orientation. Narver and Slater, (1990) suggest market orientation consists of three behavioural dimensions, namely, customer, competitor and inter-functional coordination. Others (Day, 1994; Deshpande, Farley, \& Webster, 1992; Pitt, Caruana, \& Berthon, 1996; Shapiro, 1988) have also added their views in support.

Despite the various interpretations of the market orientation construct, Jaworski and Kohli (1996) found they almost have common themes embedded in their definitions; firstly, all identified the customer as a core constituent. Directly relating to the first, they all recognised 
a focus outside the organisation (i.e. external to the boundaries of the organisation). In addition, all authors unanimously acknowledged the importance of not simply claiming that customers are important, but engaging in activities that will create superior value for the customers. Finally, all the authors suggested the external dimension of market orientation encompasses more than gathering information from customers: it also includes competitor activities, industry regulations and other market forces which shape customer needs.

The field of market orientation has grown significantly over the past 25 years to the point where almost every element of an organisation has been examined in relation to market orientation (e.g. market orientation versus culture). Hence, while there are several dimensions to a firm which are considered truly market-oriented(see Day, 1994; Kohli \& Jaworski, 1990; Narver \& Slater, 1990), for the purposes of this thesis, a particular focus is given to the literature which establishes evidence for the differences between market-oriented and customer-led businesses and the implications for new product development and innovation.

According to Slater \& Narver (1998), a market-oriented business is characterised by long term commitment to understanding both expressed and tacit customer needs and to the development of innovative solutions that offer superior customer value. Drawing on an extensive body of research, Slater and Narver identify that market-oriented businesses embody the following:

- Acquiring and evaluating market information

- Creating superior customer value through the dissemination of this information throughout the organisation

- Market-oriented firms are much more likely to be generative learners (rather than adaptive)

- They combine traditional market research tools with other techniques such as an emphatic design process to discover latent customer needs

- Work closely with lead users (early adopters)

- Conduct market experiments for generative learning, the outcome which is then is used to enhance the development of offerings

- Escape the tyranny of served markets by looking for 'Blue Ocean' (i.e. gaps in the market without the existence of a competitor). 


\subsection{Customer-led vs. Market Oriented}

As noted at the outset, one of the significant differences widely cited in literature is how an organisation comes to understand customer needs: customer-led businesses tend to focus more on the expressed needs of current customers, whereas market orientation extends further to unearthing latent needs that customers themselves are not able to articulate. Frosch (1996) recognises this as core rigidity in $R \& D$ programs leading to tunnel-vision product development initiatives that lack strategic outlook beyond present customer needs. The problem with this inherent bias towards expressed needs is that it often contributes to incremental improvements to established market requirements. The result? An output that is unlikely to offer sustained competitive advantage. This is particularly relevant in the context of a new venture that seeks to gain traction in a market with incumbent players.

Christensen and Bower's (1996) case-based analysis of the impact disruptive innovation has on industry evolution indicates that organisations who listen to their customers too closely are unlikely to achieve or maintain industry leadership. In the context of a new venture, one can argue that being the "disruptive newcomer" is probably the most assured strategy for the long term success of the new venture. Achieving this necessitates a particular focus on emerging customer segments (as opposed to existing segments) and conducting proactive market research on potential customers' unarticulated needs (versus listening to current customers' articulation of existing needs) (Kopelle, 2004).

Another common distinction is the process that a firm implements to discover and learn about customers. Slater and Narver (1998) argue that customer-led organisations utilise traditional market research techniques while the market-oriented approach goes one step further and combines traditional research methods with proactive research techniques, such as emphatic design to observe customer behaviour as they interact with their products and services in a natural setting. More recent studies (Atuahene-Gima, Slater, \& Olson, 2005; Narver, Slater, \& Maclachlan, 2004) have shown a strong correlation between proactive market-oriented culture and new product success. However, customer-led culture has shown little association with either innovativeness or new product success. A proactive market orientation here refers to "a set of behaviours through which a business attempts to discover, to understand, and to satisfy the latent needs of customers" (Slater \& Mohr, 2006). 
A further defining feature is that customer-led organisations tend to cater to mainstream customers, while market-oriented businesses work closely with lead users. These 'visionary' customers have needs that exceed what is currently on offer, thus they are very accepting of early concepts, proving a good test bed for new innovation before making it available to the more mainstream customers pragmatists (see Hamel \& Prahalad, 1994; Hippel, 1986; Tabrizi \& Walleigh, 1997). More about lead users is discussed under the banner of 'Earlyvangelists' in the next section of this chapter.

In summary, the academic literature makes clear distinctions between customer-led and market-oriented approaches to customer development. On the one hand, customer-led businesses are concerned with expressed or existing customer needs. Further, this approach works well for iterations (incremental improvements) and continuous innovation of existing products or services. Market orientation on the other hand, consists of a long term commitment to understanding both expressed and tacit customer needs and the development of innovative solutions that offer superior customer value. The latter is seen as an important advantage that new ventures should possess if they are to 'disrupt' incumbent competitors.

\subsection{The Lean Startup Methodology Framework}

Having established the importance of market orientation for innovativeness and new product development, this section presents the Lean Startup Methodology Framework (LSM) used to guide the MATE Enterprise development in 2013. Steve Blank pioneered the customer development model which is one of the principle foundations of the LSM. His book "The Four Steps to the Epiphany", from 2006, describes a process for new ventures to test and refine business model hypotheses by interacting with customers. Eric Ries popularised the LSM in his book "The Lean Startup" from 2008. In more recent years, a number of other authors have also contributed to the LSM body of knowledge. In particular, Rob Adams (2010) “If You Build It Will They Come" and Furr and Ahlstrom's (2011) "Nail It Then Scale $I t$ " have been extremely influential in my role, as the Customer Development Lead within our enterprise.

The LSM has gained a huge following in recent years, particularly amongst startup communities worldwide as the favoured methodology for discovering and learning customer 
needs. The LSM promotes early customer engagement as a method for validating the various assumptions in a startup's business model.

The process is similar to those which are described by other authors such as the Nail-it-thenScale-it (Furr \& Ahlstrom, 2011), the Ready-Aim-Fire (Rob Adam, 2010) and Blank's (2006) Customer Development Model which is depicted in Figure 2 below.

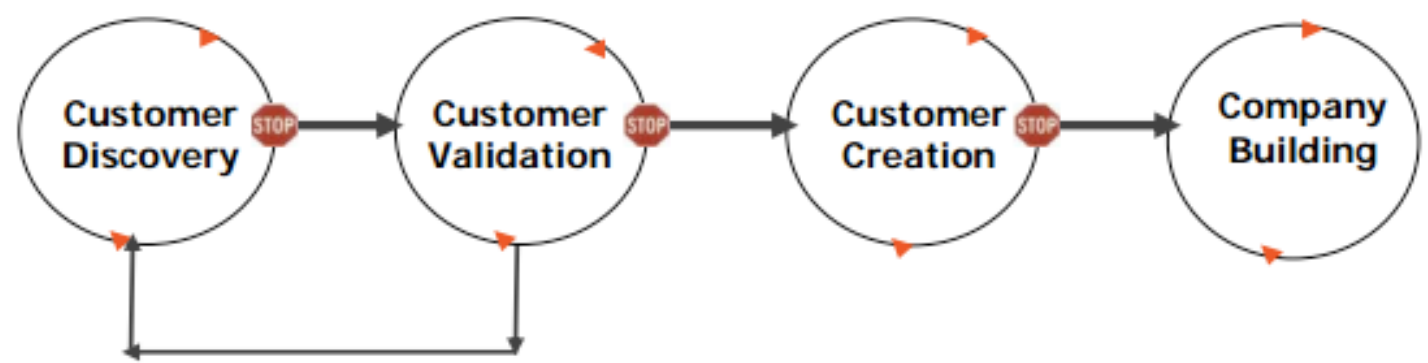

Figure 2: The Customer Development model by Blank (2006, p.27)

Blank's Model is made up of four iterative phases, indicated by the arrows on the circles. The core wisdom behind the iterative process favours learning and discovery over the temptation to execute the next phase of the cycle and prematurely move closer to scaling. This means going through each cycle multiple times if need be, until key assumptions are validated (Blank, 2006; Furr \& Ahlstrom, 2011).

The first phase, customer discovery, focuses on discovering who the customers are for an envisioned product/service. This initial validation stage is a chance to find out if the problem, solution and customers in your vision are a match. The second phase, customer validation, requires that a "repeatable and scalable" business model is developed. The signal is when a group of repeatable customers with a repeatable sales process that yield a profit are found (Blank, 2006). Customer creation concerns building on the early success of the company by creating and driving customer demand into the sales channels. Finally, in the company building phase, the focus is on growth instead of learning and discovery. The structure grows more formalised as separate functional departments are created, although this may happen gradually (Blank, 2006).

Furr \& Ahlstrom's (2011) approach is similar with the exception of Blank's first phase (customer discovery), further separated into two different steps. As shown by Figure 3, the first stage specifically focuses on discovering if there is a 'pain': a pressing customer need. The authors proclaim if there is a significant pain one can attract enough customers to 
establish a successful business (Furr \& Ahlstrom, 2011). Upon understanding the problem, the task of validating potential solutions can begin.

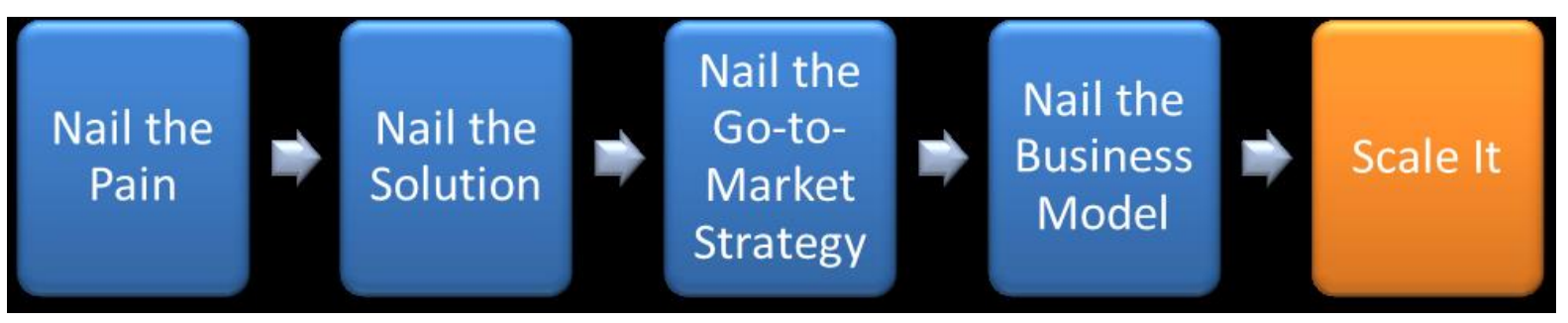

Figure 3: The Nail-It-Scale-It Model (Furr \& Ahlstrom, 2011, p22)

Rob Adams' (2010) Ready-Aim-Fire methodology follows a similar approach, although it must be noted he offers the most hands-on techniques relative to the rest of the authors. In the ready phase, the focus is on identifying if an idea or a concept is worth pursuing. The process starts with high level market scanning that considers the current market trends, industry experts' opinions and competitor analysis to ascertain how attractive an opportunity is. The aim phase encompasses the first two stages of Furr \& Ahlstrom (2011) approach. Here Adams (2010) heavily focuses on understanding the 'problem' and no product shape or features are mentioned. It is only when clear evidence of a market opportunity is established that a company starts thinking about possible solutions. Finally, the fire phase is a combination of Blank's customer creation and company building steps. In essence, this phase forces you to think about how you will drive demand and subsequently scale the business model in order to harness the full potential of the market opportunity.

\subsubsection{The Core LSM principles}

There are fundamental principles commonly provided by all the authors of LSM literature (Adams, 2010; Blank, 2006; Furr \& Ahlstrom, 2011; Ries, 2011) used in the development of the MATE Enterprise. These principles have been summarised below.

Get out of the building: Ever since being coined by the pioneering Blank (2006), the mantra "get out of the building" (p.47) has grown to epitomise the lean startup movement. One of the critical differences between an existing company and a startup is that one is already executing a business model while the other is searching for one (Blank, 2010). Entrepreneurs must therefore accept that all they have on day one is a series of untested assumptions and hypothesis about how the company will create value for customers and itself. Therefore, 
instead of writing intricate business plan, the lean startup methodology requires that entrepreneurs "Leave guess work behind" (Blank, 2010, p.18) and put those assumption to the test by engaging with potential customers as early as possible. Getting out of the building is not to ask customers what they want, but to bridge the gap between the entrepreneur's vision and realities that exist in the customer's world (Ries, 2011). This is about removing the emphasis from what is happening internally with the organisation, to going out and searching for answers.

Learning \& discovery: Ries (2011) argues that a startup should be viewed as a temporary entity whose sole purpose is to learn and discover a scalable and repeatable business model that delivers value both to the customer and consequently the organisation. The learning necessary to achieve this goal is scientifically generated through experiments designed to test hypotheses. Validated learning with a solid empirical foundation is viewed as the unit of progress indicating that the startup is making progress towards building the thing customers want and will pay for (Ries, 2011).

Minimum viable product: an effective method of generating validated learning is to build an offering with a minimum feature set to the market as soon as possible. Adams (2010) and Furr \& Ahlstrom (2011) refer to this prototype as Minimally Acceptable Feature set and Minimum-Feature Set respectively, although the most commonly used term is Minimum Viable Product (MVP) (Ries 2011). The MVP is characterised by the minimum feature set that drive customer purchasing decision. By differentiating between the "must-have" features and "nice-to-have" features a company can substantially reduce lead time to market. Ries (2011) argues this version of the product should enable the company to go through a complete cycle of the Build-Measure-Learn loop with the least amount of development time in the process.

Iterative design: The lean startup methodology is underpinned by iterative design over traditional "big design up front" development (Blank, 2006). The Customer Development Model was the first to pioneer this process, taking inspiration from John Boyd's Observe, Orient, Decide and Act (OODA) loop developed as military strategy for winning battles (cited in Blank, 2010). Ries (2011) refined the process into what is commonly known as the Build-Measure-Learn loop. The main objective is to iterate through this cycle without reducing the quality of each cycle (Ries 2011). 
Pivot: Ries (2011, p. 149) describes pivoting as "a structural course correction designed to test a new fundamental hypothesis about the product, strategy, and engine of growth". Pivoting must be considered if one or more of the business model hypotheses are rendered invalid after contacting potential customers. 


\subsection{The Lean Startup Methodology Process}

Gustafsson \& Qvillberg's (2012) examination of barriers to implementing the Lean Startup Methodology in early-phase manufacturing ventures also found significant similarities between the views of authors they chose to represent the LSM, which match those covered here with the exception of Adams (2010) who did not feature in their study. Their findings suggest a possible amalgamation between the common principles of different lean startup authors, to arrive at the synthesis of a final framework that represents the LSM practices of these authors.

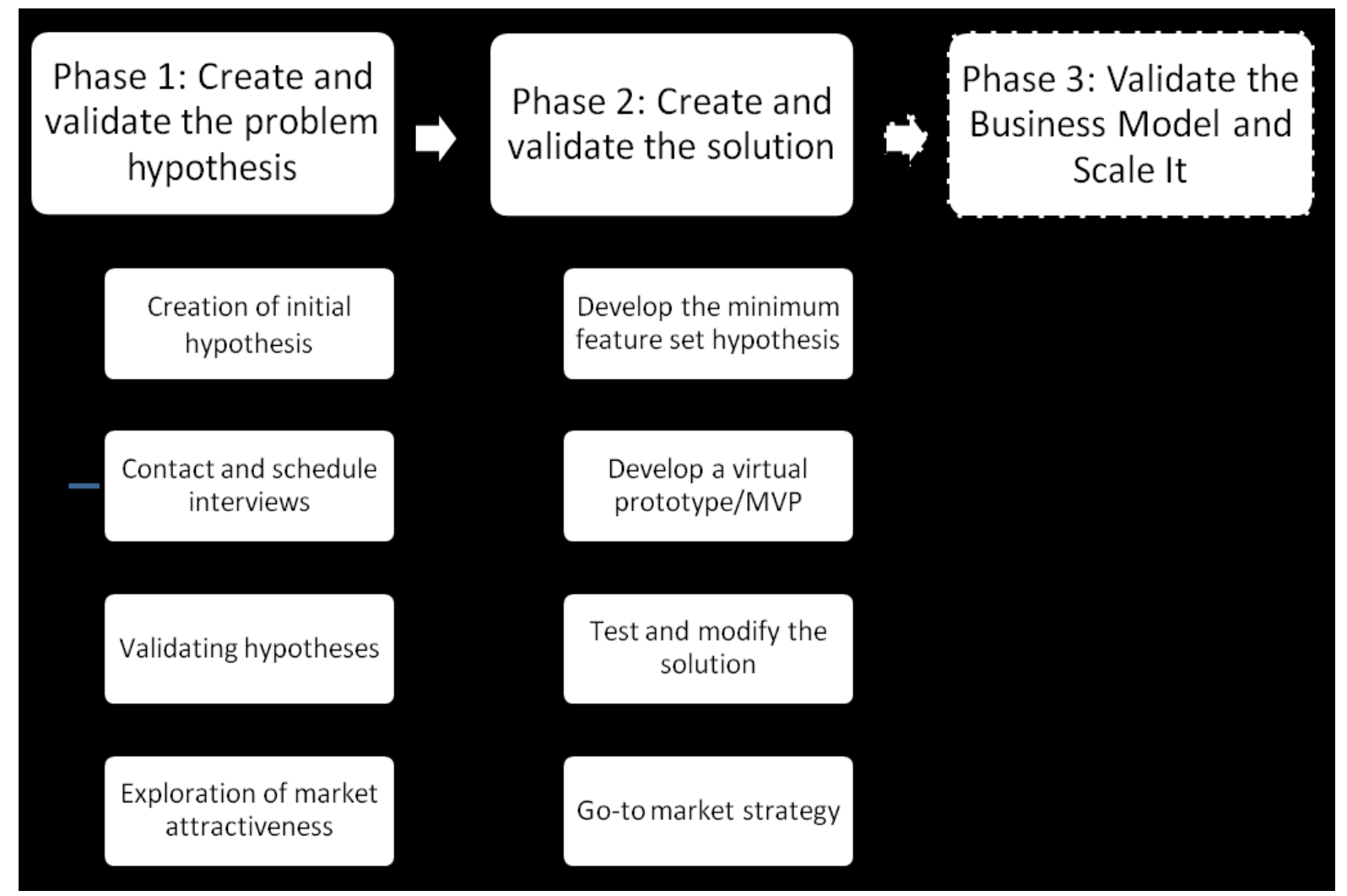

Figure 4 LSM Process by Gustafsson \& Qvillberg (2012, p.22)

Gustafsson \& Qvillberg's (2012) process consists of three phases which begins with the creation of an initial hypothesis and ends with validated business model and scaling. Each phase is further broken into four steps although their study only focused on the first two phases.

I propose a small refinement to Gustafsson \& Qvillberg (2012) LSM process in light of additional views from Adams (2010), whose methods have been influential in the MATE Enterprise development. While Adams (2010) is mostly in agreement with the other lean 
startup authors on best practices, Adams (2010) institutes an additional phase of secondary market research that precedes the three-phase process proposed by Gustafsson \& Qvillberg (2012). It is worth noting that elements of the secondary market research is captured in the “Exploration of Market Attractiveness" step of Gustafsson \& Qvillberg's (2012) process, however their findings support evaluating the attractiveness of a market much earlier:

"The attractiveness of the market has rather low focus and is dealt with in later stages of the process...The earlier a segment that is not attractive is dismissed the less resources is spent and thus more resources is available for new tries and the likelihood for success increases.” (Gustafsson \& Qvillberg, 2012, p.69)

The results from Gustafsson \& Qvillberg's (2012) research coupled with the added wisdom of Adams (2010) strongly justify an additional phase to the start of the LSM process. The added phase focuses on identifying if an idea or a concept is worth pursuing based on a high level market scan. Denoted as "Secondary Market Research", the purpose here is to quickly and objectively qualify the market and decide if an opportunity warrants further investigation.

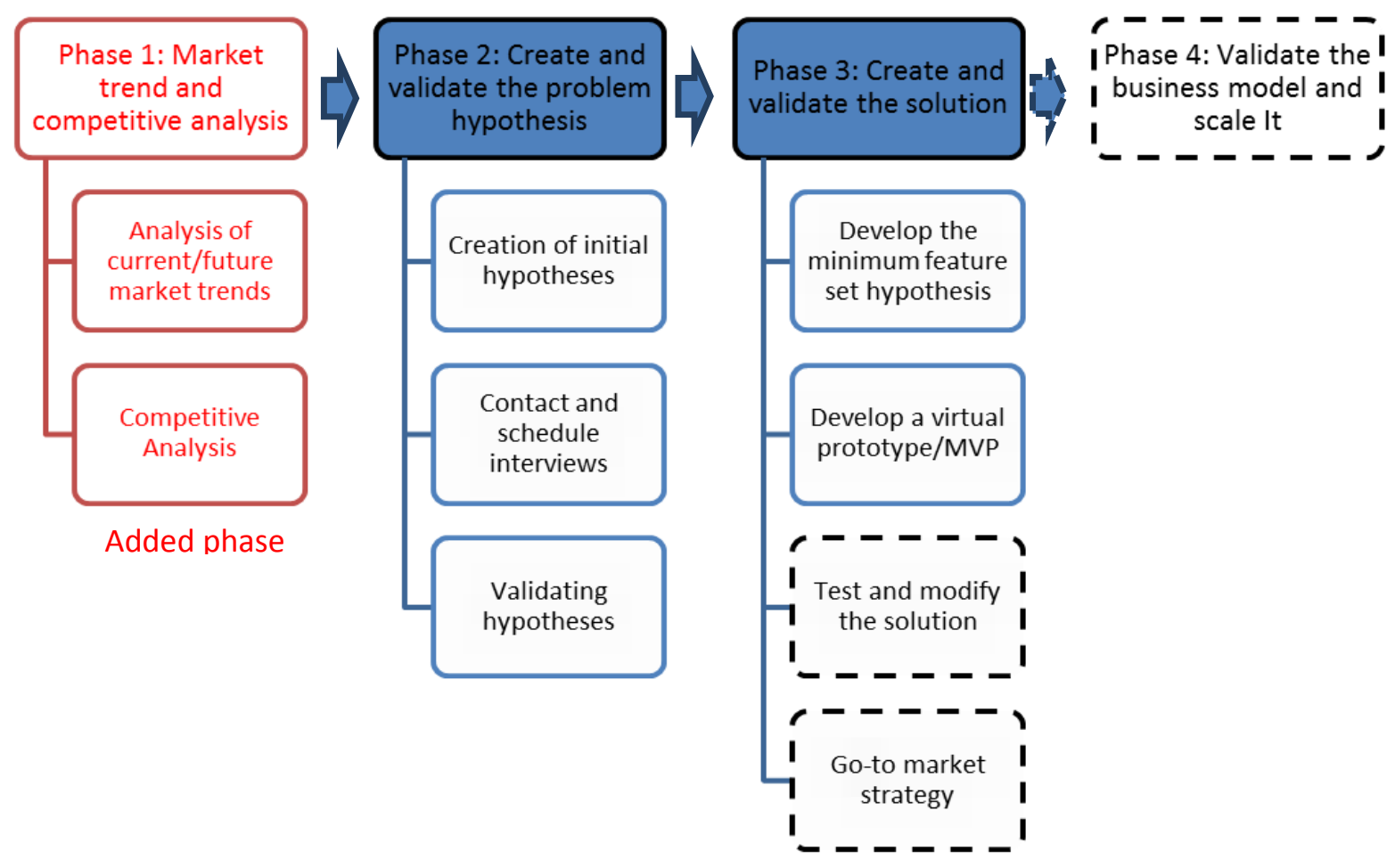

Figure 5: Refined LSM Process 
Figure 5 shows a four-phase-process adapted from Gustafsson \& Qvillberg's (2012) threephase LSM process. The process starts with the added phase of secondary market research (market trend \& competitive analysis) and ends with validation and scaling of the business model. During the development of the MATE enterprise, the team only reached as far as developing a first physical prototype and carrying out few initial tests. Therefore the scope of this thesis is limited to the evaluation of the first three phases of the LMS process, presented in more details below. The broken lines in the figure show the phase and steps not described here ${ }^{1}$.

\subsubsection{Phase 1: Market trends and competitive analysis}

The LSM process begins with secondary market research; what's happening in the market today and in the near future. Achieving this requires considerations for market trends and competitive analysis.

Current/future Market Trends: Two aspects that need to be considered here are the size of the market and growth rate (Furr \& Ahlstrom, 2011; Adams, 2010). Furr \& Ahlstrom (2011) suggest that a target market should be large enough to accommodate a new entrant. The larger the market, the lower percentage of market penetration required to generate enough revenues to make the venture worthwhile. Strong revenues are easiest in a faster growing market where the market is on the growth side of the product adoption curve (Adams, 2010). At this side of the curve it is always less costly to acquire new customers who have just entered the market, rather than taking existing customers from a competitor (Adams, 2010). On the flipside, a slow-growth market is more difficult to enter. Products that enter in the later part of the adoption curve (namely late majority and laggards) face the additional challenges of price sensitivity, incumbent competitors with established customer base and domain knowledge. Blank (2006) also stresses the importance of obtaining qualitative market knowledge through customers, key industry influencers or secondary sources.

Competitive analysis: Before investing time and resources, entrepreneurs should assess competitors already in the market. Adams (2010) asserts that competition needs to be viewed as a "net positive". The presence of competitors in the market is indicative of a viable commercial opportunity. Therefore, startups need to take full advantage of their presence by

\footnotetext{
${ }^{1}$ Interested readers can find more details about the boxes with dotted lines by referring to "If You Build it Will They Come" (Adams, 2010), "The Four Step to the Epiphany" (Blank, 2006) or "Nail it Then Scale it" (Furr \& Ahlstrom, 2011).
} 
learning from them in every way possible. If feasible, the entrepreneur should purchase from them and carry out a product analysis. Adams (2010) also suggests assessing product quality, features offered that are important to customers, and hints and indication of the level of customer loyalty. The next level of analysis required is to look at substitute products. A substitute encompasses anything that maybe used in place of your offering. Furr \& Ahlstrom (2011) suggest finding big problems as a way to mitigate substitutes, because customers can usually live with smaller problems by finding ways around them. A thorough competitive analysis will also include economic analysis: "the economic return needed to consider making purchase decisions" Adams (2010). A business needs to consider the return on investment of an offering for prospective purchasers. This can be saving time, money or energy.

\subsubsection{Phase 2: Create and validate the problem}

Creation of initial hypothesis: This should be driven by the company's basic mission and core values Blank (2006). Ries (2011) also states that the initial hypothesis should be based on the founder's vision. When augmenting changes to a hypothesis, the decision for change should be based on empirical evidence (Blank, 2006). Adams (2010) differentiates the various sources of an initial idea/concept by favouring those that originated from domain knowledge: more than 10 years of experience in the targeted industry.

The complexity of hypothesis varies depending on the author. Furr \& Ahlstrom (2011) introduce two different hypotheses; monetizable pain and the big idea hypothesis. The monetizable pain hypothesis focuses on the need experienced by customers. The big idea hypothesis is the solution to the pain observed and why it is better than existing solutions. Ries (2011) also introduces two hypotheses, the value and growth hypotheses, together referred to as leap of faith assumptions. The value hypothesis tests whether a product or a service delivers values to customers. The growth hypothesis focuses on how new customers will discover the new product.

Validating the hypotheses requires finding potential customers. Blank (2006) argues the importance of first finding customers who are innovative and have needs more advanced than the mainstream customers. He calls these customers "earlyvangelists", describing them as "The most important customers you will ever know" (Blank, pp.34 2006). 


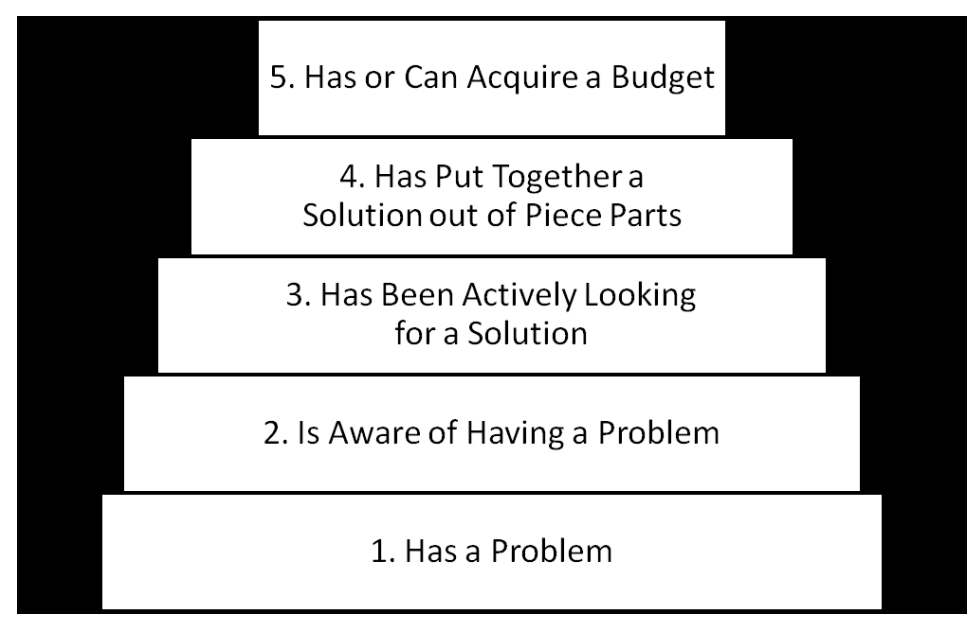

Figure 6: Characteristics of earlyvangelists

Once the hypotheses have been formed and a group of potential customers have been identified, it's time to "get out of the building" Blank (2006) and generate validated learning by testing the assumptions on real customers. All four authors heavily emphasise the externality element of the market validation.

Contact and schedule interviews: Initial contact with customer should be made either by telephone or email (Blank, 2006; Furr \& Ahlstrom, 2011). It's important to keep a statistic record of the hit rate; the percentage of customers who agree to a meeting or phone interview. The hit rate is used as an indicator of customer pain levels. It is more likely that a significant problem worthy of further investigation has been found when $50 \%$ or more new customers return cold calls (Blank, 2006; Furr \& Ahlstrom, 2011). In situations where the results are below the bench mark, the hypothesis needs to be revised in order to find a more pressing problem. These early interviews can inform the sales strategy: how easily you get through to customers now is an indication of how easily you will be able to sell to them (Adams, 2010).

Validate hypotheses: The three main techniques covered by the LSM authors are Face-toFace interview, Telephone interview and Electronic Survey. According to Blank (2006) the suitability of different techniques depend on the complexity of the hypothesis. Complex hypothesis require several interviews, therefore the face-to-face interviews should be used first to probe the most important questions while latter interviews focus on establishing deeper understanding of the day to day life of the customers. Furr \& Ahlstrom (2011) suggest the used of telephone interviews to validate simple hypothesis. Adams (2010), in contrast, argues that the use of direct interview (i.e. telephone or face-to-face) techniques depends how narrow the target audience are: the broader the target audience, the more appropriate the use 
of electronic surveys. Once an attractive market segment has been identified, the use of direct interviews will yield more value by enabling more intimate understanding of customer needs.

The validation process should include at least 100 direct interviews with target market before entering the solution development phases (Adams, 2010). Furr \& Ahlstrom's (2011) process also puts the emphasis on the monetizable hypothesis which purely deals with the problem, while the big idea hypothesis works in parallel to gather information about the kind of solution the potential customers need. The data collected through the big idea hypothesis establishes the feature set of the solution in the next phase. Ries (2011) tests the problem hypothesis with the help of a prototype in the next phase of the process. In the initial stages of validation, he suggests creating customer archetype by contacting the mass market with problem. However, this can be regarded as a market assessment exercise rather than validating the problem.

There are several apparent themes embedded in the different approaches to validating hypothesis: firstly the importance of using appropriate interview techniques during different stages of validating the hypothesis. Furthermore, there is also an indication of the importance of segmenting the market to arrive at a set of customers, whose needs can be intimately studied in order to produce an offering that is more specific to that set of customers. The other key point here is the importance of direct interview techniques as an important tool for answering the most important questions in a hypothesis.

Validating the hypothesis should be treated as an iterative process and should first be tested on small patch of customers before increasing the sample size Adams (2010). The insights from each round of interviews are used to update the business model canvas. After going through several iterations, if there is a lack of interest from potential customers a pivot should be considered to find a new problem (Furr \& Ahlstrom, 2011: Ries, 2011).

Create and validate the solution: Once a significant problem has been identified and validated both Furr \& Ahlstrom (2011) and Adams (2010) methods require assessing the attractiveness of the market segment. This requires overlaying the data collected during validating the hypothesis with the data from the secondary market research to ensure the market remains attractive even after macro factors such as market trends and competitive analysis are taken into account (Adams, 2010). 
Provided all the data analysis checks out, the next step is to develop the solution. All the authors describe the phase as an iterative process with the objective of putting together an offering that satisfies customer needs while requiring the least amount of development time. This phase is broken into three steps: develop the minimum feature set hypothesis, develop a virtual prototype/MVP, and test and modify the solution.

Develop the minimum feature set hypothesis: In order to create an offering that both satisfies customer needs while also requiring the least amount of development time, it's necessary to reduce the number of features incorporated into the offering (Adams, 2010; Ries, 2011; Furr $\&$ Ahlstrom 2011;). This requires creating a minimum feature set: the most focused set of features that will drive customer purchasing decisions (Furr \& Ahlstrom 2011). Adams (2010) recommends categorising each possible feature into two categories: "must-have" and "nice to have" based on the data collected in the later stages of the hypothesis validation phase. He argues the minimum feature set should predominantly consist of must-have features.

The ultimate form of market validation is "getting someone to open their wallet and part with their money" and the best way to do this is to get a product out, fast (Adams, 2010, p.5). The minimum feature set is used to develop the MVP which represents the core set of features that drive customer purchase. The assumption is that if those basic features are put in the hands of customers, their most pressing needs are addressed. If there is a lack of set of features that customers are willing to pay for, the market segment should be abandoned or a new problem should be identified for solving (Furr \& Ahlstrom 2011).

Develop a virtual prototype/MVP: As previously stated; the minimum feature set is used to develop the first prototype. Ries (2011) argues the best way to start the process of learning about customers is to place a rapid prototype in their hands. Minimum viable product (MVP) is the most effective strategy for a fast and quantitative market testing of a product or product feature (Ries, 2011). Based on the minimum feature set, the MVP has just those features that allow the product to be deployed, and no more (Ries, 2011). The Fundamental goal of the MVP is to test the Leap of Faith hypothesis stated earlier (Ries, 2011). Though the MVP is not necessarily the simplest product imaginable, it is simple enough to enable fast changes with the least amount of effort. Each cycle is used to conduct further tests and find out which attributes are perceived to be value-adding by customers ((Ries, 2011; Furr \& Ahlstrom, 2011). Spending additional time perfecting features is viewed as "wasteful" given the 
underlying assumption that a startup does not have complete knowledge of who their customers are and therefore what product attributes are truly worthwhile (Ries, 2011).

The first MVP is not always a ready to use product, nor is it formulaic. It requires judgement to figure out, for any given context, what MVP makes sense (Furr \& Ahlstrom, 2011; Ries, 2011; Blank, 2006). For instance, a virtual prototype can serve as meaningful first MVP. The Virtual prototype can be anything from a PowerPoint presentation to video as long as it serves as a meaningful method of gaining deeper understanding about the effectiveness of a proposed solution (Furr \& Alhstrom, 2011).

The 'real' prototype or MVP is created from the validated results of either the minimum feature set or the virtual prototype. The process of developing the MVP is different to traditional method of product development. One of those differences is the perception of quality as measure of success. Ries (2011) argues too often traditional businesses focus on producing high quality experience for customers as primary driver. This presupposes that the startup already knows what product attributes will be perceived as high quality by customers; a risky assumption to make in new ventures still discovering and learning about their place in the market. Instead the emphasis should be placed on discovering which product attributes customers require to be high quality (Ries, 2011). The MVP is an opportunity to turn the insights from the virtual prototype into a real product that captures the essence of the tested minimum feature set (Furr \& Ahlstrom, 2011). Once the prototype is in the hands of real customers, there should also be an exercise of observing customer interaction with the product, as this can often raise important questions that haven't previously been considered (Adams, 2010). Likewise, Ries (2011) acknowledges that customers cannot be trusted to articulate all of their problems; therefore observation can fill this gap using a prototype.

Test and modify the solution: The iterative process of testing and modifying the MVP slightly differs depending on the LSM author. The most notable difference is the number of processes used. Furr \& Ahlstrom (2011) evaluation of the MVP consists of three separate processes: the virtual prototype, the prototype and the finalised solution. Ries (2011) uses the single process of build-measure-learn feedback loop illustrated by Figure 7. As previously stated, the startup's main objective is to minimise the time spent going through the loop during each cycle of iteration. Although the number of validation processes varies between the authors, the basic principles are the same: Build a prototype, measure its effectiveness as 
solution and generate learning outcomes which can be used in the next phase of iteration. Therefore it's safe to assume that the build-measure-learn feedback loop is representative of all the LSM authors' views of the validation process.

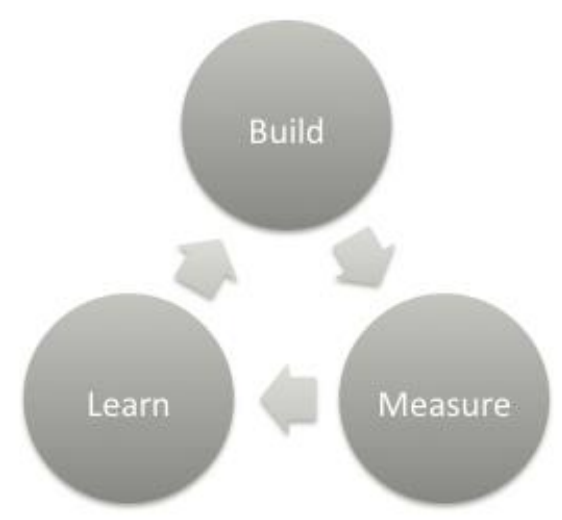

Figure 7: The Build-Measure-Learn-Feedback Loop

There are number of guidelines to keep in mind during this phase of the LSM process; Furr \& Ahlstrom (2011) emphasise the importance of structuring interviews in the solution testing phase in a manner that elicits innovative thoughts from customers. He argues that it's possible to have "customers innovate for you" by asking questions that are relatively complex in order to gauge deeper thinking while avoiding questions that lead to simplistic 'yes' or 'no' answers (Furr \& Ahlstrom 2011). Further, two additional factors that increasingly grow in importance are price points and breakthrough questions. As the prototype testing progresses, how much customers are willing to pay for the solution increasingly becomes more important to determine. The breakthrough questions go step beyond and seek to gain purchasing commitments from customers. The breakthrough could also consist of a commitment to trial a product (Blank, 2006). "These factors are a measure of whether you have nailed the solution, and the most reliable answer is cash from customers" (Furr \& Ahlstrom, 2010). 


\section{Methodology}

\subsection{MATE Research Approach}

To a large extent the research approach and design is pre-formulated around how the MATE program is setup: Students form teams of three to five members that bring together a pool of interdisciplinary expertise. The teams then take on research projects with real commercial potential as learning vehicles to explore the challenges in creating a successful technology enterprise, while also adding value to the research by exploring the commercial potential of technology. Each student occupies a specific role within the enterprise that is aligned with their background education or field expertise. Each student also has an independent research focus that looks to contribute to the body of knowledge in his/her chosen field of expertise. The projects thus serve both as vehicle for exploring the commercialisation process of a researched technology and as a tool to gather data for individual research objectives.

In contrast to traditional research paradigms, the set-up of the course does not start with a research proposition and hypothesis which is then followed by data collection to specifically answer research questions. The primary and driving objective of the project work was to advance the commercial value of the business concepts. Therefore, it is by the 'doing' that answers to research questions are found. In fact the data used to answer my research questions is a by-product of the market research undertaken for commercial purposes. For example, the documented interviews and my personal notes both provide a rich source of textual data for identifying points in time when a particular orientation, customer-led or market-oriented, may have been the dominant feature even though this was not the driving purpose behind the collection of this data. However, given how the research programme is set up, this emergent, rather than intended, fit was always going to be the case with research questions forming during and after data collection.

\subsection{MATE: A Participatory Action Research}

While the MATE program has a unique method of research that is valid in its own right, the essence of the practical base and the self-involvement of the participants in the research process are inherently similar to a qualitative research approach known as action research. O’Leary (2004, p. 139): describes action research as: 
"A research strategy that pursues action and knowledge in an integrated fashion through a cyclical and participatory process. In action research, process, outcome and application are inextricably linked."

Action research is an alternative method of understanding and gaining meaningful insights into complex social systems, such as the entrepreneurial process of commercialising promising research, which cannot otherwise be reduced to a test of causal because of the crucial role context plays in the investigation of such systems (Baskerville \& Lee, 1999).

Participatory Action research (PAR) is an alternative philosophy of social research, traditionally associated with the field of rural and community development that focus on social transformation. According to Denzin and Lincoln, (2003) there are three main characteristics that set PAR apart from other traditional research: shared ownership of research projects, collective-based analysis of social problems and an orientation towards collective action.

In recent times the application of action research has been broadened to include fields of study that extend beyond social research (Denzin \& Lincoln, 2003). The method has grown to become a general strategy for institutional change through closely working with people in order to solve a problem and implement sustainable changes (Salkind, 2010). In order for PAR to be applicable to wider fields of research, O'Leary (2004) argues that the original social-centric characteristics of PAR need to be translated into generic principles that encompass wider research applications which take place in a variety of different contexts. In line with this argument, there are five basic principles used to qualify research method as PAR (O’Leary, 2004):

1) Addresses practical problem

2) Generates knowledge

3) Enacts change

4) Research is participatory in nature

5) Reliance on a cyclical process

In the remainder of this section, I will present my argument as to why the MATE research design can be qualified as a valid qualitative method of research that falls within the boundaries of Participatory Action Research based on the principles outlined above. 
To consider research study as PAR, the first principle requires the research to embark on solving a practical problem. The MATE programme seeks to address the practical problem of marrying scientific research with commercial product development. This practical problem is explored in two ways: From a high level, the programme seeks an answer to this problem through the establishment of multidisciplinary teams that are capable of developing viable product concepts. Being the first of its kind in New Zealand, the course explores this 'uncharted territory' that has huge implications for the future economic growth of New Zealand. The importance of the research is well recognised by some of the thought leaders in the field of scientific research and commercialisation in the country.

“We have 10 [advanced technology] companies exporting \$4 billion. Why not 100? One hundred inspired entrepreneurs can transform this country into a creative, innovative dynamo." - The late Professor Sir Paul Callaghan

"The programme places an appropriate and perhaps unique balance between understanding and skill building. This will deliver great insight for students of the practical aspects of commercialising technology, the potential formation of actual startup companies, and the real-world challenges of being a successful entrepreneur." - Steve O'Connor, CEO, Creative HQ, Wellington

On an individual level each student had the expectation to undertake research objectives from the perspective of his/her disciplinary role within the team. To answer both the individual research questions and the overarching question posed by what the programme is trying to deliver, my team and I took on three 'life' projects over the course of a year. The LSM process was used to practically assess the commercial value of the various projects we took on. My individual research questions assess the implications of using the LSM model as a scientific approach to discovering and learning about the needs of potential customers, and whether that leads the venture in becoming customer-led or market oriented.

The second and third principles of PAR go hand in hand: generating knowledge is required in order to enact change, equally the enactment of change should lead to the production of knowledge (O'Leary, 2004). This is in line with Denzin and Lincoln's (2003) assertion that "action learning" is a core constituent of action research. Action Learning refers to the fundamental ideal of bringing people together to learn from each other's experiences while also collaboratively solving a problem. 
These principles are demonstrated by the way we worked on different projects; we talked to customers in order to generate knowledge in the form of market information. The market information was analysed and then used to implement changes to the value propositions and hypotheses. Depending on the significance of the market findings, sometimes we made slight adjustments while other times we pivoted to explore a completely different market. Further, as already discussed in the literature section of this thesis, the LSM process we implemented have these principles entrenched in its fundamental values of continuously acquiring market information that will steer the direction of a project.

The fourth principle of action research is the participatory method of investigation, where researchers collaborate with practitioners and other stakeholders. Contrary to many other research paradigms, PAR works with rather than on or for the researched (O'Leary, 2004). As the researchers, we integrated ourselves by closely working with the project champions and their respective teams on different projects. We called upon their domain knowledge while also continuously sharing important market intelligence in order to inform future directions of the research projects and eventually product development.

We also closely collaborated with various other stakeholders such as Victoria Link (Vic Link), the commercial arm of Victoria University that oversees any commercial activities resulting from academic research. Vic Link is entitled to one third of any intellectual property generated from academic research projects within the university; therefore Vic Link formed an integral part of our wider team. Effectively, various parties came together with a minimal distinction between the "researched" and the "researchers" (O'Leary, 2004). Being part of the research as well as conducting the research has its own implications, which I will discuss later in the critique of action research while also alluding to the differences between PAR and the MATE research design.

The Final Principle of Participatory Action Research is a cyclical process that manifests as knowledge emerges. The process gives preference to experiential learning which requires continuous refinement of the research method based on data interpretation and insights acquired in earlier cycles. This principle closely aligns with that of 'action learning' described earlier (Denzin \& Lincoln, 2003) and also with Lewin's (1946, cited in Salkind, 2010) Model of action research. 

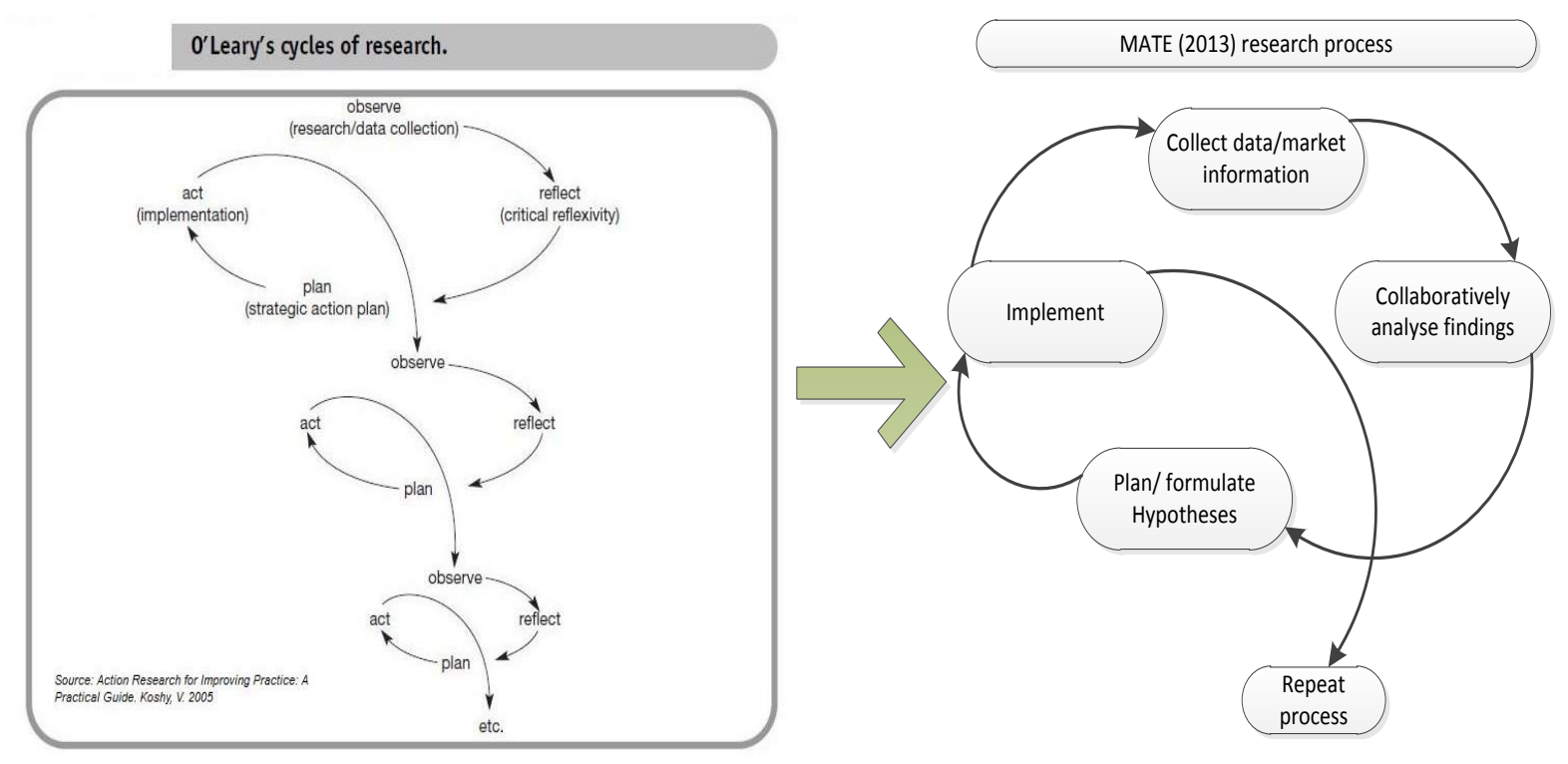

Figure 8: The cyclical similarities between MATE research process and O'Leary's (2004, p.141) cyclical research process.

The cyclical process we experienced is largely influenced by the iterative nature of the LSM process, which we used to validate the different projects we worked on. As illustrated by Figure 8, the research process we undertook was one of continuous refinement using findings from our interactions with the market. During these interactions, we sought to collect data that will enable us to either validate or invalidate business hypotheses we formed in an earlier cycle. Each member in the team was entrusted with the validation of an aspect of the hypothesised business model. The team came together once or twice a week to reflect on findings and analyse the data. The main questions asked during the analysis stages consisted of what have we learnt? And what more do we need to find out? Vic Link and the project champions were also invited to these meetings in order keep them up to date on the current status of market findings. In the planning phase, we either reformulated business hypotheses and/or we re-strategised to determine alternative paths of finding the data we need to validate/invalidate business hypotheses. The latter occurred if previous plans proved fruitless. This process was repeated until either product market-fit was achieved or the team discontinued working on a project.

\subsubsection{Critique}

Having discussed how the MATE research design demonstrates the five principles of participatory action research, I will now focus my attention towards recognising some of the 
common criticisms against action research. The fact that my research method closely follows the core principles of participatory action research also suggests much of the common critique applies to my specific context. Moreover, methods by which these concerns are mitigated (to an extent) are also elucidated, while also recognising limitations that may be specific to the MATE research design.

The advantages and disadvantages of action research have been debated and well documented in the literature (Cavana, Delahaye, \& Sekeran, 2001; Creswell, 1998; Denzin \& Lincoln, 2003; McNiff \& Whitehead, 2002; Miles, Huberman, \& Saldana, 1994; O’Leary, 2004; Reason \& Bradbury, 2001; Salkind, 2010; Silverman, 2006). One of the commonly cited criticisms is that action research lacks rigour in certain contexts, imposing "academic discourse over participants" (Salkind, 2010). This often leads to participants becoming unwittingly influenced by the theories being implemented by the researchers.

In our case this was not a massive concern. As a matter of fact, sometimes we did not have the level of influence over the project champions and their research teams as we would have liked partly due to conflicting priorities: their objectives were driven by discovery and advancement of knowledge in a certain field of academia, where as we assessed results based on commercial merits. However, given the project champions willingly put their projects forward for us to explore, by default the research was always going to be one of collaboration and participation by all parties in question. Prior to many of the decisions made along the way, we first consulted with all of the different stakeholders. Therefore, I believe our positions as researchers were not ones of significant influence or power.

Another common criticism (often posed by quantitative researchers) is action research's perceived inability for generalisation owing to small sample sizes. PAR as a method of research is time consuming in nature, hence researching numerous cases simultaneously is near impossible due to the level of self-involvement required on the researcher's part. However, studying a situation in its natural context necessitates working with a small sample size in order to generate in-depth understanding. In this polarised debate, Salkind (2010, pp.7-8) offers the following counter-argument:

“...is any claim of replication possible in studies involving human researchers and participants... and is this desirable in contributing to our understanding of the social world? " 
In line with this argument, it is important to understand that PAR does not set out to produce generalisable data; rather it offers the opportunity for exposure to meaningful insights that might otherwise be unavailable to the researcher. Furthermore, the findings from the question of whether the LSM model favours to customer-led or market-oriented approach is not intended for generalisation to every given situation where someone is using the LSM. On the contrary, any findings from my research are only generalizable within similar contexts and dissemination of the findings is likely to be applicable to those who are in a similar situation. Therefore, generalisation comes second to capturing the richness of a unique human experience that represents a slice of the social world.

Another commonly raised concern in regards to action research is the participatory nature of the researcher. It is argued that there is a subjective nature resulting from being an 'actor' in the research where one's own personal values and perceptions can affect both fieldwork as well as the interpretation of information (Cavana et al., 2001; Creswell, 1998; Denzin \& Lincoln, 2003; Miles et al., 1994; Salkind, 2010; Silverman, 2006). To mitigate this, a process of rigorous and constant reflection during the research is recommended in order to discover instances where biased values and perceptions can insert themselves (Salkind, 2010).

As discussed in the previous section, we established this to some extent through on-going weekly team meetings to discuss findings and plan the next phase of the research. These meetings were often characterised by spirited debates amongst team members as to what a certain piece of new information means and how that alters the course of the research. Further, through facilitation of an experienced business strategist (and also LSM practitioner), only the fact-based opinions prevailed, therefore reducing the level of individual perception and personal values manifested in the research findings.

There are also potential weaknesses specific to the MATE research design that must be acknowledged. Firstly, putting commercial value first has the major implication of not necessarily steering the research in the best direction for answering research questions but instead the course of action taken is primarily driven by the likelihood of commercial success. Therefore, in hindsight, it may be argued that there was a better course of action to take in order to generate better quality data for answering my research questions. However, I view this interplay between solving a practical problem while also seeking answers to a 
research question as a positive 'dilemma' because it is by solving the problem that I have been able to gain access to the data which will shed light on my research queries.

Another limitation that should be mentioned is the origins of the data: As previously revealed, each member occupied a specialised role within the team there by generating their share of the data used to answer research questions. This could means that there are a lot of contextual details missing from the data which my team members might not have necessarily identified; given each member's research focus was different. Even so, this may not be a significant issue as we collectively planned what information needed to be found each step of the way. Hence, it is fair to say that as a team we practiced high level of transparency amongst each other and we did our best to make records of the findings, which was disseminated across the team and stakeholders.

\subsection{Data Sources}

As mentioned in the previous section, there are various sources of data available which paint a clear picture of the team's approach to customer development during different projects. These sources consist of the following:

MATE Group Report: Collation of the project findings into chronological document that depicts the actions taken, outcome, and decisions made. The document is authored by the four students involved in the research. Therefore, re-counts of events are based on the agreed viewpoint. This offers solid foundation to say which direction things were heading, although the case lacks some of the specific details from interaction with customers. These, more intimate, details of events are available in other sources such as the shared Google Documentations and personal notes of key events and meetings.

GoogleDrive Documents: throughout the research phase of the programme, each member of the team documented detailed notes of conversation with almost every person we spoke to in the process of validating each project. The findings were discussed amongst the team in one of the two weekly mentoring sessions. This offers more textual data of what people have said in response to interview questions. The interpretation of this data through the lenses of my research objectives, in combination with other sources of evidence, provides a good platform for recognising periods when we might have taken customer-led or market-oriented approach to discovering the needs of potential customers. 
Enterprise development Journal: is another source of data which I will utilise in seeking answers to my research question. The journal was a course requirement for documenting weekly progress and participation in the enterprise. This document holds details of key events as well as lessons learnt at various stages of the enterprise development. There are also personal notes from meetings in their raw form before I typed them up and made them available via Google shared drive. Furthermore, we arranged visits from various individuals ranging from industry specific experts to business mentors. I took the liberty of taking notes of their feedback and advice on various projects, which I plan to use as vehicle for my own reflections on various incidents in the research process. This data will predominantly be used to strengthen my conclusions and lessons learnt. 


\section{Data}

This section presents the data from the projects used to explore the LSM denoted in the literature section. The LSM process was used to develop all projects; implementing as many of the steps and phases as possible in order to take the concepts closer to a commercial point. The decision to abandon a given project was made once all possible avenues of commercial opportunities had been exhausted. The main objective of the data presented is to highlight periods when the team might have become customer-led or market oriented. Comprehensive details of the cases are available in the Appendix 1.

\subsection{NacreTech}

Dr Kate McGrath and her team from the school of Chemical and Physical Science have developed a composite material based on synthetic Nacre (commonly known as mother of pearl). The material in its simplest form demonstrates similar properties to native hard tissue (bone), making it ideal for the use in artificial hard tissue implants. However, this was not a product yet but a new researched technology that was searching for its first commercial applications. With this in mind, we started looking into different applications for the first proposed prototype: an injectable dental gel for veterinary use, suitable for filling voids created by tooth extraction.

In consideration for the first phase of the LSM model, an in-depth analysis of both current and future market trends was conducted. It was found that the overall market trends for the veterinary industry, especially the companion animal segment, seemed to be growing and showing several partially effective solutions existed already which warranted further investigation.

The initial hypothesis for the first commercial application of NacreTech technology was based on the project champion's vision that "there is a need for veterinary dental void filler that protects the extraction site following tooth extraction, thereby preventing infection and reducing healing time". The solution hypothesised was based on the first proposed prototype: “an injectable dental gel”. 
In testing the hypotheses, we contacted 25 veterinary specialists across the country by phone and interviewed them to gain a better understanding of how effective our prototype might be in its intended use. We soon learnt that whilst this was a growing market internationally, generalist veterinarians who perform the majority of dental work on companion animals rarely use void fillers, as the site normally heals well without the use of specialised material. One particular interviewee stated the following when quizzed about veterinary dental void fillers:

"If the socket is healthy, it will heal fine on its own. If it's diseased and infected you definitely don't want to put anything in there that might trap infection and prevent healing. Extraction does run the risk of fracturing the animal's jaw and trauma or a strong bite could result in serious fracture, but I have never seen this occur." - Veterinary specialist

In cementing our understanding that there is not a pressing need for void filler, another veterinarian added the following:

"I haven't noticed any difference in outcomes when not using a filler; in the vast majority of cases there aren't complications with an extraction and the site heals amazingly well with no treatment. I haven't ever had to refer a patient on to a specialist for dental treatment." Veterinary specialist

The general comment after hearing about the potential use of nacre in this space was one of intrigue; however the majority of respondents were quick to point out that there is no foreseeable value in using this product. This was mainly due to the effectiveness of current treatment methods, coupled with the existence of a number of substitute products. These findings are echoed in Dr Craig Hunger's comments:

"I use Consil to rebuild bone that has been lost in severe cases of periodontal disease, although this isn't done very often. Occasionally I will insert a gortex barrier with an antibacterial agent. An infected socket can be filled with a slow release antibiotic such as doxycycline periceutical gel. As New Zealand and Australia are small markets we don't have access to the same products as other countries, sometimes we have to make up our own." Veterinary specialist 
This customer feedback was also directly responsible for our decision to broaden the scope of our market research from focusing purely on dental void filler to considering how nacre might be used in orthopaedics. By analysing the data from interview, we found that there was an 'expressed' need for a product that aids in fracture management. The people we interviewed also clearly articulated what additional properties/features would influence their purchasing decision in switching to new product:

"Ideally if something was osteoinductive it would be useful for (GTR) and for fracture management. Everyone who makes these products wants them to be used in extractions; I do not use them much there." - Veterinary specialist

To further investigate the bone grafting market, a member of the team was sent to attend the World Small Animal Veterinary Association (WASA) conference where he conducted face to face interviews with Veterinarian Specialists. This time focusing on bone grafting, we learnt that there are several synthetic substitutes in the market, although none of them perform as well as an autograft ${ }^{2}$ procedure. Thus, in order for synthetic nacre to achieve a distinctive competitive advantage over existing synthetic substitutes, the material needs to behave like an autograft. These findings were summarised in a report and passed back to the R\&D team so that they could refocus the research if they wish to make it commercially viable in the future. Importantly, the report also provided a list of validated market requirements that will enable NacreTech to achieve the same gold standard as an autograft.

This marked the end of our involvement in the project as we could not offer any more value until the development has reached a clinical trial stage. We therefore sought another project to assess and a new market to explore.

\subsection{Sound Concepts}

In many ways the next project, Sound Concepts (SC), presented similar challenges to NacreTech: we looked to find a commercial application for a developed piece of technology

\footnotetext{
${ }^{2}$ Autograft - The current gold standard for bone grafting, an autograft is bone tissue taken from a patient's own body. While this produces a reliable result, it requires that the patient undergo an additional surgery to harvest the graft material, often increasing healing time for the patient.
} 
with known properties. Natasha Perkins, a Senior Lecturer from the School of Architecture at Victoria University, and her team have developed a series of architectural products that combine design with acoustic performance. The initial technical research has resulted in the development of two tested prototypes: The 'Triform', a hanging acoustic baffle system designed to absorb a range of sound frequencies and reduce reverberation within interior spaces, and the 'Pod', a freestanding breakout space for primary school children to retreat from the noisy class room environment.

We simultaneously looked into schools and offices: schools, because of the inherent effects of noise in children's ability to learn, and for office workers to concentrate and work productively. We hypothesised, "there is a need for design-led acoustic products in schools and offices to reduce sound and reverberation while also increasing the aesthetic appeal of environments". We also hypothesised that "the Sound Concepts solutions will provide a system that delivers superior acoustic performance with an added feature of design."

In the process of validating both the problem and solution hypotheses stated above, we spoke to 27 schools across the country, interviewing school property managers and principals. These early conversations generated enough data to invalidate schools as a potential first market for the SC products. The trends in the data collected indicated that whilst schools take acoustics into consideration and rate it as being relatively important in a class room fit-out; schools also tend to be restricted by budget constraints. The sample of responses presented below demonstrate the direction these customers were leading us.

“[Acoustics] is important but no money to do anything about it! [Therefore] Acoustics makes up a small percent of overall budget" - Property Manager

"Teachers have expressed concerns about the "Management of Noise" in the classroom rather than the noise itself" - Property Manager

"Would be very interested in a product that can reduce sound at an affordable rate, and can get around financial constraints from the Catholic office" - School Principal

"I rank importance of acoustic performance at 8/10 - can't have teachers competing with echoes" - Corporate Services Manager 
Despite the fact that a need has been identified, the limited budget of schools coupled with dominant and well established competitors significantly undermined the attractiveness of the school market. One particular competitor worth noting is Autex who is the 'runaway' market leader in New Zealand. I recall one particular conversation I had with a school property manager who affectionately spoke about the Autex acoustic products:

\section{"We poured money into Autex [products] ... and it was worth it" - Property Manager}

Overall, the trends identified in the data suggested that the school market was very small and further restricted by the limited school budgets and fierce competitive activities. We therefore pivoted to purely focus on the commercial office space. We understood from an initial market scan, that commercial office architects also consider acoustics important when fitting out offices spaces. This early indication was used to probe further into the acoustic requirements of offices.

We contacted the complete "panel of customers" (Furr \& Ahlstrom, 2011), ranging from Acoustic Engineers, Architects to the end users such as office managers and property managers. The findings are captured in selected passages from various interviews below.

"It all comes down to one person, the marketing guy next to the accounts guy." - Acoustic Consultant,

\section{"Architects are traditionally cautious when it comes to new materials" - Interior Designer}

The acoustic consultant's comment above is a synopsis of the real issue underpinning the need to address acoustics in office environments. Changes in the industry from traditional office layouts, where spaces are separated, to more open plan offices which house all workers in the same space has meant that disturbance has become a real issue. Traditionally architects applied standard solutions which include ceiling tiles, wall insulation and acoustic blankets to dampen the level of noise in the office. However, open plan offices have the unique challenge of everyone working in a singular space which further intensifies the level of noise. This called for a different approach:

"Can't see something like this being used in the initial fit-out of an office, the room/space will be designed with acoustics in mind rather than using a product to solve it" - Architect 
The trends in the data collected showed that the industry was experiencing a shift in the mind-set of how acoustics is tackled in open plan environments. The findings indicated a move away from applying additional acoustic materials, to changing the behaviour of office occupants through the creation of diverse environments intended for different uses. One of those environments is known as a semi-private meeting space. Here employees can take phone calls, collaborate and have discussions without disrupting colleagues at their workstations. Moreover, while all of the different parties we spoke to agreed that this was the leading method of improving open plan environments, we also noticed differences in opinion amongst different groups in what the end users value the most.

There is often a 'disconnect' between what architects perceive as an appropriate solution and the core requirements of the end users... [Which] leads to too many custom solutions not being used as intended. - Property Advisor

"It's about creating a certain look and feel that shows the organisation's culture and value" - Commercial Architect

"I'm putting my name against the work, it has to be something I'm is happy with...It's about creating the wow factor" - Interior Designer

The feedback from various industry stakeholders at times seemed like there was an element of competing interests in terms of what different groups perceived to be value adding. Architects tend to pay particular attention to the 'vibe' of the environment they are creating as an important feature. On the other hand, property advisors are more concerned with the practicality of the solution and whether it meets the everyday needs of office workers.

However, by combining the various interview data and performing trend analysis, we were able to extract a list of market requirements for a semi-private meeting solution. These include:

- Simple to install (not requiring building consent, contractors or major construction)

- Lightweight (can be moved easily by one person)

- Reconfigurable for use in a variety of different spaces

- No higher than $180 \mathrm{~cm}$ (to avoid the need to move sprinklers or to get building consent) 
- Freestanding without the need for additional supports such as bolts or ceiling suspension.

- Have acoustic properties that dampen noise

- Data/power options built into the structure of the product

- New Zealand made

- Environmentally friendly

- Cost effective

By this point it was becoming clear that there was market opportunity in open plan offices, specifically better ways of creating semi private meeting spaces. However, measuring the value propositions (acoustics and aesthetics) of the SC products against the requirements of semi-private meeting spaces showed lack of unique selling point that would set this concept apart from established furniture suppliers. With this in mind, the team decided to set aside all existing prototypes and preconceived solutions in order to build on the opportunity we had identified.

\subsection{HYV}

HYV is the result of the extensive data we gathered during the SC Project. The project was founded by the MATE team in response to the market opportunity for better furniture solutions we discovered in open plan offices. Background information on this project is available in appendix 1.

The team began by constructing a survey designed to further refine the market requirements of semi-private meeting spaces. We needed to determine the relative importance of the requirements in order to distinguish between the "must have" and "nice to have". The survey primarily targeted end users (office managers) as a way of identifying core product features, commonly known as a minimum feature set (Furr \& Alhstrom, 2011).

\section{"How important are the following attributes? Please rank the list of attributes in order of importance." - Examples of the survey questions}

We use the results of this survey to help guide the creation of a virtual prototype. This consisted of a digital rendering that sought to capture user requirements, primarily focusing 
on the functionality aspects. The concept was made up of two panels, straight and curved, that when clipped together creates a semi-private area within a larger space.

In order to complete the LSM process of build-measure-learn, we put the virtual prototype in the hands of potential customers. Their feedback further solidified our understanding of user requirements and the core product features that will drive purchasing decisions. The customer response also gave us an encouraging signs to commence developing a MVP.

\section{"Being able to reconfigure our meeting spaces would really be useful." - Office Manager}

In order to develop the MVP, we needed to identify a niche market that will serve as a 'testbed' for the greater market. We selected a niche market made up of organisations that were displaced by the 2013 earthquakes in Wellington. We picked this segment based on their positive feedback when shown the virtual prototype. The majority of these organisations were currently in temporary premises that lacked any real collaborative environments. Teams used a central table to host informal meetings and other collaborative activities. Furthermore, their requirements were also simple enough for us to be able to use our internal resources and capabilities to put together a prototype.

"Something like this would definitely be ideal for smaller meeting of 3-5..." - Office

\section{Manager}

After constructing the MVP we invited small group of potential customers to come and view the MVP. This was an opportunity to observe potential customers interact with the MVP in a setting that resembles an open plan office. Observing potential customers interact with the MVP helped us to better understand their needs in a way that surveys and interviews alone could not. Details such as the ideal number of occupants, the range of furnishings and the level of acoustic dampening expected were gathered and refined during the MVP showcase.

The initial MVP generated interests from several organisations. One particular organisation, Lighting Lab, offered to purchase seven units that are similar to the MVP. They saw value in a temporary and reconfigurable solution that will enable them to adapt their workplace to a variety of different needs.

More information on the HYV project and future development plans is available in the MATE Group Report. 


\section{Analysis}

This section presents the analysis of the MATE team's experiences of following the LSM process. The characteristics of market-oriented and customer-led businesses (depicted in the table below) will be used to identify when one of the approaches was present or dominant. These characteristics are derived from the literature reviewed in the earlier sections of the thesis.

\section{Customer-led}

\section{Market-oriented}

- Focus on expressed needs

- Short term focus (of addressing expressed needs)

- Use of traditional market research techniques

- Focus on existing markets

- Focus on established customers (value network)

- Incremental improvements and continuous innovation

- Adaptive learning

- Reactive strategic orientation

- Direct enquiry of customer needs (as oppose to probe and learn)
- Focus on both expressed and latent customer needs

- Focus on executing longer term vision as well as short term

- Combine traditional market research techniques with other techniques such as emphatic design and design thinking

- Work to discovering gaps in the market without existing competitors

- Continuous acquiring and evaluating of market information

- Dissemination of market information throughout the organisation

- generative learning

- Proactive strategic orientation

- 'Probe and learn' through market experimentations to generate learning outcomes

Table 1: Characteristics of Customer-led and Market-oriented businesses 


\subsection{NacreTech}

The NacreTech technology had the potential to be disruptive in the orthopaedic industry, as other synthetic materials currently in the market do not resemble natural bone as well as the NacreTech technology does. Therefore, in the beginning of the project, our intent was to establish a market-oriented business by disrupting existing competitors in this space. However, focussing on finding a commercial application for a developed technology turned out to be a customer-led undertaking.

As we explored the first commercial application of the first prototype, the customer-led approach started to become dominant. The problem as well as the solution hypotheses was pre-formulated by the project champion and her $\mathrm{R} \& \mathrm{D}$ team. This meant that the prototype was developed with a particular group of customers in mind and our job consisted of evaluating if the project champion's vision matched the needs of an existing market.

The nature of the first prototype was also very short-term in its focus, as part of the project champion's objectives included using it as a proof-of-concept for the wider application of the technology. Further, given that the solution was pre-defined, the focus was always going to lead to finding an 'existing market' as opposed to working to discover gaps in the market. Therefore, NacreTech's dental void filler as a product had the inherent danger of being incrementally different in terms of functionality from existing solutions, making it likely solution for addressing current needs instead of a novel or emerging customer need.

As we interviewed veterinarian experts across the country, focusing on evaluating expressed needs, we relied on these potential customers to be able to articulate the issues they face in dental surgery. Our intention was to be market oriented, but because of the uncertainty surrounding what the market was, we had no option but to pay close attention to what customers were saying. Therefore, by listening too closely to potential customers it became very easy for us to be co-opted into what the customers wanted presently, and in a sense we became customer-led. The lack of domain knowledge also played a part in the dominance of the customer-led approach. Much of the discussions were extremely technical nature, which required a certain level of knowledge in the veterinary dentistry domain to decipher the feedback. Thus, at times we became reliant on potential customers to provide a degree of the domain knowledge, which further strengthened their influence over our approach. 


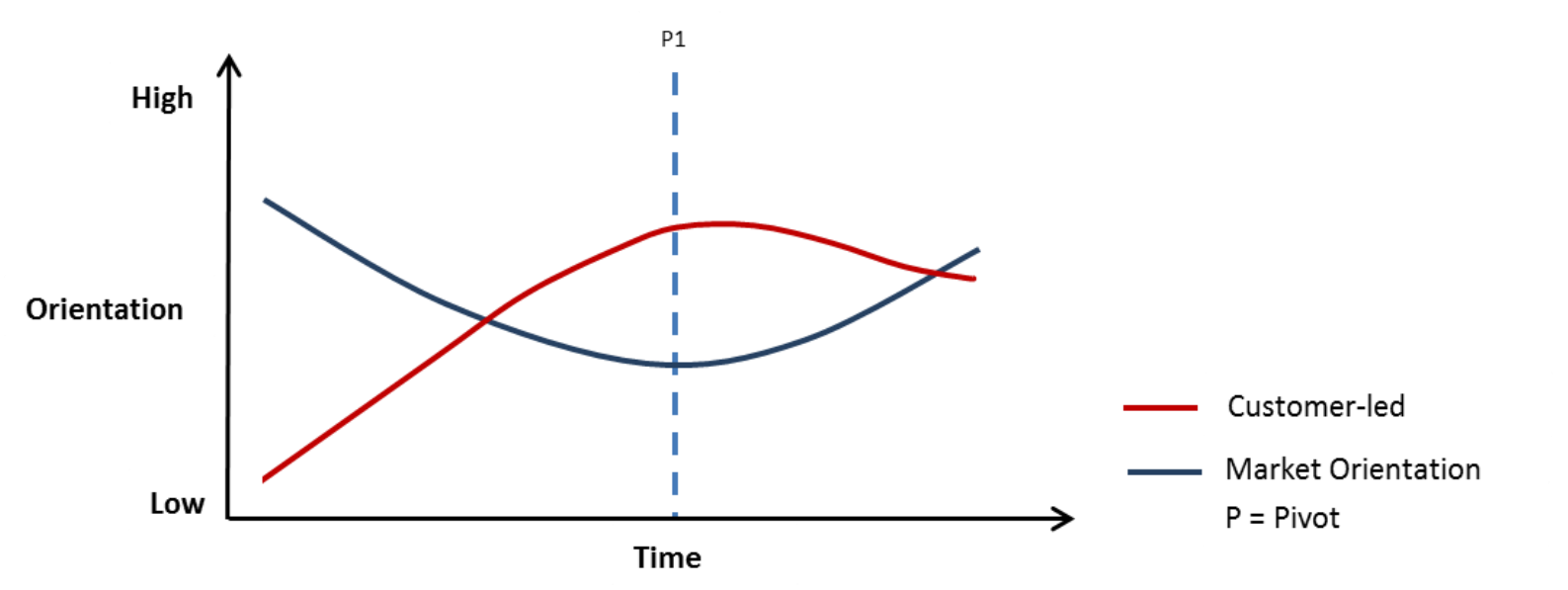

Figure 9: Summary of the extent to which each orientation was present during the course of the NacreTech project.

Interestingly, the decision to broaden the application and potential uses of the NacreTech technology, originated from the feedback of veterinary experts. It was in the process of exploring the potential uses of the dental void filler that we discovered the need for a synthetic bone grafting material that offers similar benefits to an auto-grafting procedure. As indicated by P1 in Figure 9, pivoting away from the dental void filler triggered a change to become more market-oriented. From this point, we focused on what properties the nacre material needed to display in order to achieve unique of difference. The technology did however; still require a certain level of development in order to constitute the desired properties of an auto-graft procedure. Therefore, our focus also changed to thinking about the long-term. Hence, the customer-led approach, though still present, was not as dominant as when we were focused purely on the dental void filler.

\subsection{Sound Concepts}

When we first started working on the Sound Concepts (SC) project, there were similarities to NacreTech; both in terms of the development stage of the technology as well as the type of market validation required. The market orientation is shown to be quite high in figure 10, as a result of the entrepreneurial mindset of the team and their goal of finding a repeatable and scalable business model. Moreover, in the words of Christensen (1997, p.18), we were not "held captive" by established customers, and therefore the exploratory nature of our quest justifies the dominance of the market orientation. 
Again, this project too had prototypes developed and we were tasked with finding an immediate need for what was already developed. On that basis, we were again susceptible to potential customers leading us. Both the Pod and TriForms prototypes were at a final stage of development, therefore the LSM process was used to find a viable market for the existing products.

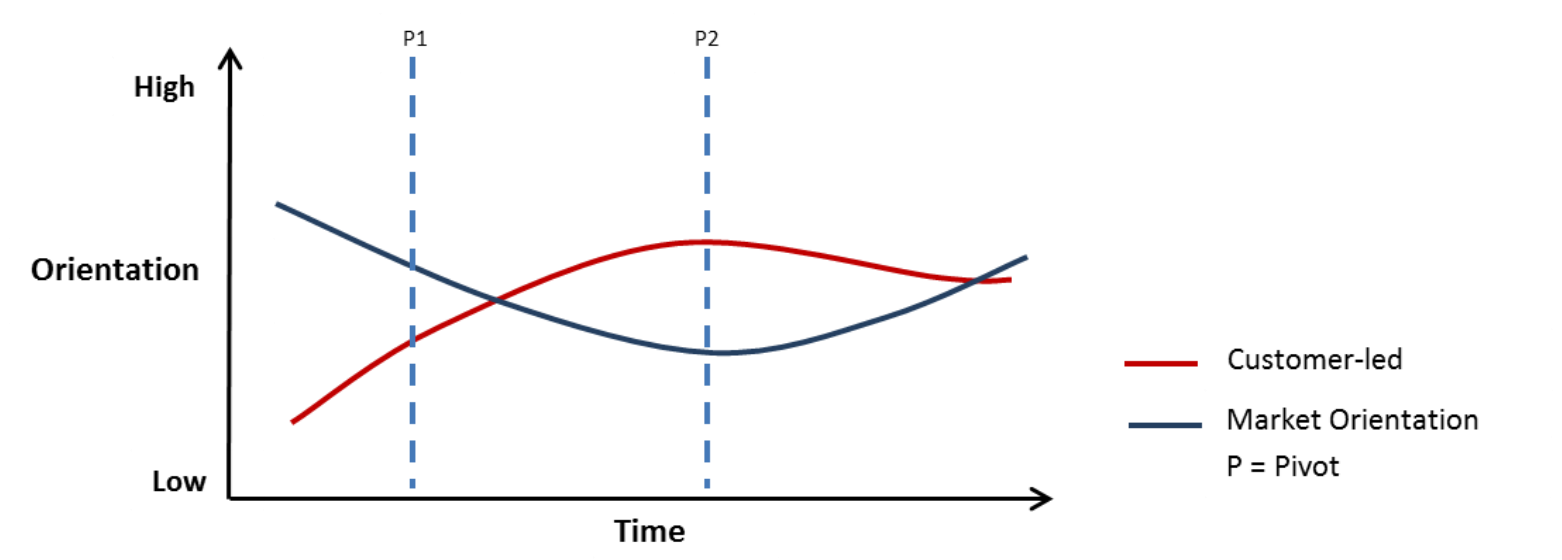

Figure 10: Summary of the extent to which each orientation was present during the course of the Sound Concepts project.

As we explored the school market, the customer-led approach was again the dominant approach. The market validation was structured to capture an existing or expressed need for a design-led acoustic product. Again, this was a short term focused as we looked to find immediate takers of the developed products. As indicated by Figure 10, the market orientation continued to suffer resulting from the significant focus on 'expressed needs'. This trend seemed to continue even when we pivoted away from schools in favour of offices (P2). Hence, while the market segment had changed, the team continued the search to find an existing market for the acoustic TriForms.

As described in the data section, the team interviewed a range of industry stakeholders in attempt to discover potential customers for the SC products. The data revealed SC products did not meet the requirements of all the groups that play a role in office fit-outs. In talking to all of these different groups, however, we gained an extensive amount of knowledge in the industry that enabled us to consider potential gaps in the market, when the team decided to no longer pursue the SC products.

As indicated by $\mathrm{P} 2$, the pivot away from the SC products seems enable market-oriented approach to discovering customer needs. No longer constrained by the 'established' needs of potential customers such as architects and designers, the team was able to go on a quest to 
understand the market requirements for creating semi-private meeting spaces. What is more, instead of listening to the present needs of one set of customers, we triangulated the feedback from all parties to extract meaningful insights regarding the industry's shift away from the traditional office setting to an open plan one. Though we still maintained a high level of contact with the customers, the manifestation of the customer-led characteristics (see Table 1) were not as profound as when focussed on finding a market for the SC products.

\subsection{HYV}

The trends observed in HYV are distinctively different to those of Sound Concepts and NacreTech. This project came about as a result of an opportunity identified in semi-private meeting spaces within offices; therefore we able to flow the LSM process as prescribed by the authors to begin with a problem hypothesis instead of prototypes. Consequently, the team worked to discover what this potential gap in the market actually entailed. As demonstrated by Figure 11, the two approaches seemed to be somewhat balanced; where the team continually acquired customer feedback without necessarily being too attentive to the needs of an established group of customers.

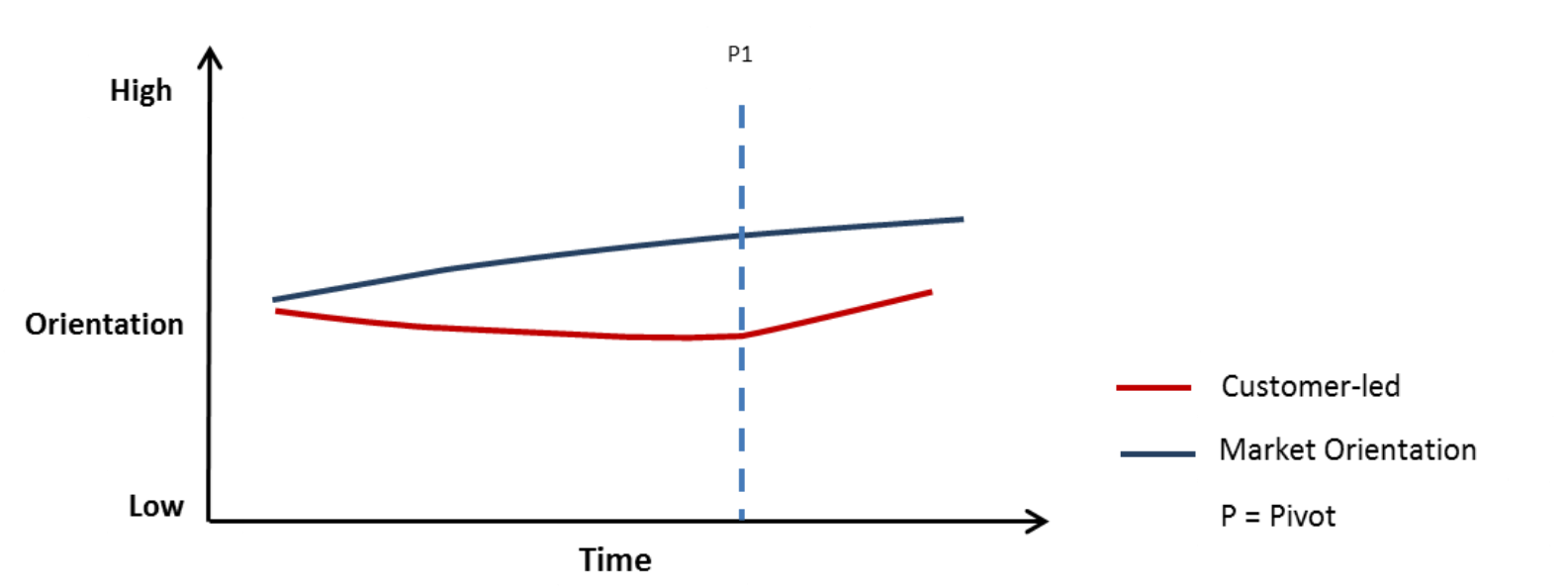

Figure 11: Summary of the extent to which different approaches were present during the course of the HYV project.

The constant increase in our market-oriented approach to understanding customer needs is partly attributed to the greater ease of domain knowledge acquisition relative to the NacreTech project. During the course of SC and HYV, the team developed a considerable level of industry specific expertise and useful networks with an active interest in the potential 
findings of our research into open plan offices. Therefore, the team became less reliant on seeking direct answers from potential customers and became more empowered.

It can be argued that much of the learning throughout the process of evaluating this market opportunity was generative in nature as the team continually experimented to discover new insights into what constitutes a potential semi-private meeting space solution. This is in contrast to the adaptive learning process of the other two projects; where the emphasis was on adapting a pre-existing solution to different markets. In addition, the HYV project was also driven by the execution of a long term vision to create 'versatile work environments', so our validation efforts simultaneously considered both expressed and latent needs.

As demonstrated by Figure 11, the achieved balance between a market-oriented approach and a customer-led approach was lost somewhat when the team entered the product development phase. As the MATE program's end date fast approached, the team sought to speed up the process by targeting a niche market and using the learning as a proof-of-concept. Here we closely considered the specific needs of businesses that had been displaced by the 2013 earthquakes in Wellington and those that were in the transition of moving office spaces. The needs of this subset of customers closely resembled the market requirements we had identified, such as freestanding structure and easy configuration to different spaces; however they also required additional considerations that are specific to the temporary nature of their office spaces. Therefore, customer-led orientation increased as we paid close attention to their specific needs.

Time pressures resulting from the MATE project deadline also necessitated a degree of execution before we eventually presented our findings to a panel of investors. The market orientation remained relatively constant, which indicates the possibility of co-existence between the two orientations. Despite heavily focusing on the temporary version of HYV, much of the learning gained from this is likely to also add value to any other line of products developed by the business. 


\section{Discussion}

The primary objective of this thesis was to investigate if the LSM process favours a marketoriented or customer-led approach to customer development. As such, the MATE team's experiences of using the LSM process to explore the commercial value of three research projects has been utilised to perform a reflective analysis. Overall the analysis of the data indicates that there is no direct correlation between LSM process and a particular orientation. Rather, there were other overarching factors such as domain knowledge and the level of preconceived prototype development that played a more major role in the team's approach at different points in time. These are discussed in more detail later in this chapter.

\subsection{The LSM Process}

The findings also indicate that the relationship between the LSM process and the orientations is very much dependent on the entrepreneur's approach to seeking product/market fit. Andreessen (2007) describes product/market fit as: "being in a good market with a product that can satisfy that market". Our experience shows that it is plausible to become marketoriented or customer-led when using the LSM process; however this depends on whether the product or the market is the primary driver of the validation process. In one instance the entrepreneur is deliberately looking to discover a present market need in order to align it with a pre-defined solution, while the alternative seeks to study the market in order to identify an opportunity followed by the development of a specific solution.

Both the NacreTech and SC projects initially searched for a commercial application of predeveloped prototypes. Therefore to some extent we had to modify and adapt the validation steps of the LSM process to take into account the fact that we were not only validating a problem hypothesis (Furr \& Ahlstrom, 2011) but also seeking a product/market fit for the solutions already developed. According to the LSM authors, the solution hypothesis should work in the background to the problem hypothesis. Further, product development should not be engaged until a clear market problem has been identified and understood (Blank, 2006). However, our circumstances were such that commercialising research was always going to start with a product (or at least a core piece of it), and it was our job to align what has been 
developed to an existing need. Therefore this was reflected in the type of questions we asked customers, which leaned towards eliciting information about present needs or needs customers are able articulate.

\section{Do you take acoustic performance and noise control into consideration when fitting out the interior of a classroom? Have teachers expressed concern about the level of noise in classrooms? - Sample of the validation questions}

These questions focused on investigating if there was a market need for the core feature of the products at hand. Frosch (1996) recognises this as core rigidity in R\&D programs leading to tunnel-vision product development initiatives that lack strategic outlook beyond present customer needs. Even worse, if customers reject the solution hypothesis, it's difficult to continue with the project, as was the case for the first two projects.

In contrast, there is evidence across all projects that when the team abandoned preconceived products, greater market orientation manifested. This can partly be attributed to a shift in both the mind-set of the team and in the structure of validation activities. When the LSM process was structured to investigate the market without the inherent bias towards problems which can be solved by the preconceived products, the team was able to focus on discovering gaps in the market. Further, the questions we asked tended to focus on needs that customers may not be necessarily aware of, however when probed intensely these needs tend to materialise. This is consistent with Slater and Narver (1998) distinction that market orientation extends beyond addressing customers "expressed" needs and seeks to discover "latent" needs that customers themselves are not able to articulate. The HYV project is a good example to further illustrate this point:

\section{How satisfied are you with your current open plan work environment? How interested are you in a system that creates semi-private spaces within open plan offices? - Sample of the validation questions}

Here we extensively studied an identified opportunity in the semi-private meeting spaces within offices without a predetermined solution in mind. As illustrated by the questions above, we quizzed potential customers on their level of satisfaction in order to evaluate the opportunity. Once we had confirmed that there was in fact a significant 'pain' (Adams, 2010), the team began gathering market requirements for a potential solution in the semi- 
private spaces within offices. Here we consulted customers on the requirements, but did not seek their input in envisioning or designing the product. There is evidence here that maintaining a degree of market orientation requires being able the balance the conflict of engaging the customer, without becoming led by their thoughts and opinions.

Experience in using the LSM process can play a significant role in finding the balance between listening to customers while at the same time not being led by their feedback. Comparing the validation process of NacreTech with that of SC reveals that as the team became more proficient with the LSM process, they were able to ask the right questions in order to elicit responses that were more meaningful.

\subsection{Domain Knowledge}

The findings from the data suggest domain knowledge played a significant role in the team's approaches throughout the projects we worked on. Furthermore, the level of technical complexity of the different technologies we worked with was a key determinant on how easily the team was able to acquire a various degree of domain knowledge from different markets we explored. Adams (2010; p.29) defines domain knowledge as "an individual's or team's knowledge working in a particular industry". In line with this definition, domain knowledge can be further separated into two core elements: the domain expertise in the target market or industry and technical capability within the team in terms of product development.

"Kate and her team have extensive knowledge of the synthetic nacre technology and the science behind it. Our plan is to utilise this knowledge to effectively move forward into product development of dental cement. This may include activities such as providing advice to the team on how to design and implement effective testing of our product." - NacreTech Team Plan Document

As illustrated by the above passage from the NacreTech team document, we recognised quite early the importance domain knowledge in successful product development and commercialisation. More importantly, we were under the opinion that the project champions' involvement in the market research process will provide a degree of this, especially in the technical capability department. However, what we did not anticipate is the differing objectives between the MATE team and project champions; where we looked for commercial 
viability; their primary driver was ongoing research and discovery. This often led to ineffective communication between the two parties which also meant that we did not have the much needed domain expertise as readily available as we would have liked. Therefore, the dominance of customer-led in the first phase of the NacreTech project is partly the result of listening too closely to customers as we sought to understand the technology itself through the feedback from customers. We often relied on market information both from primary and secondary sources to clarify technical matter that we did not have full grasp over. Moreover, while we could clearly identify problems in the industry and we were passionate about the possibility of fixing some of those problems, limited domain expertise meant that we lacked a real appreciation for the industry itself.

A similar pattern is also observed in the SC project in regards to the relationship between a customer-led approach and the lack of domain knowledge. One of the early challenges we faced was finding potential customers for SC. Office fit outs are characterised by a multilayered, often complex purchasing decision process where there are several parties involved. This is what Furr \& Ahlstrom (2011) term "the buying panel" which consist of end-users, technical customers and economic customers. Each group of customers we spoke to tend to hold a unique set of requirements that they believe should influence the purchasing decision. For example, comments from property advisors suggest they believe architects focus on the wrong features and the emphasis should be placed on end user requirements. We often fell into the trap of identifying one group as 'the customer', only to pivot away after a certain piece of information materialised. However by the time this was recognised, we normally had spent considerable time and effort asking the wrong questions to the wrong crowd. Therefore, lack of domain knowledge often delayed our ability to successfully focus on the correct customer. Looking back at our experience, we often took longer than needed to come to a decision in regards to what course of action the team should pursue next. In hindsight, starting with a degree of domain expertise would have saved us valuable time in the validation phase.

Market orientation requires being able to see past present customer needs in order to recognise future trends (Slater \& Narver, 1988). Put differently, the entrepreneur must engage the market in a proactive manner that moves beyond customers' expressed needs to discovering latent ones (Day, 1999). In order to achieve this however, one needs to possess a 
certain level of industry expertise that naturally allows deeper understanding of information. Remember, latent needs are characterised by a lack of awareness on the customer's behalf (Atuahene-Gima et al., 2005; Narver et al., 2004), therefore it falls upon the entrepreneur to generate meaningful insights from market information. Our experience from the SC project demonstrates this point; as we became more comfortable and knowledgeable in the industry, we were able to look at information under a 'different light'. Consequently, we were able to extract emerging customer needs in the semi-private meeting spaces which eventually led to the launch of HYV.

Another interesting observation across all three projects was the relationship between ease of domain knowledge acquisition and the level of technical knowledge which the industry operated on. The more technical the industry, the more difficult we found to acquire a level of expertise that would enable us to analyse information in a market-oriented manner. For instance, exploring the fields of orthopaedic surgeons and veterinarian doctors required more technical knowledge than office furniture industry. Therefore, one could acquire a sufficient level of industry expertise in a relatively short period of time in the latter industry.

One method of compensating for domain knowledge is to identify and develop close relationships with "lead users". This subset of customers are normally visionaries who either recognise emerging industry trends, or face needs that are months if not years ahead of the mass market (Hippel et al., 1999; Hippel, 1986; Tabrizi \& Walleigh, 1997). Blank (2006, p.29) describes these individuals as "the most important customers you'll ever know".

Over the course of the different projects we worked on, there were always particular customers who tended to show more enthusiasm than the masses. TwentyTwo Property Advisors for example played a huge role in the development of HYV. Not only did they become our first point of contact for market validation, they were also active in our research in this space. TwentyTwo Property Advisors also conduct their own research in creating versatile work environments; therefore we often counted on their expertise to help explain our primary market research results. The relationship we developed with this firm and other similar customers to some extent mitigated the lack of domain knowledge. 


\subsection{Preconceived prototype}

"Products handed off to a sales and marketing that has only been tangentially involved in the new product development process lose. It's that simple." Blank (2006, p.10)

Across all three projects, there seems to be an inverse correlation between market orientation and presence of preconceived prototypes. As illustrated by Figure 10, when the emphasis was placed on finding an existing market for the dental void filler, the LSM process seemed to favour a customer-led approach as the team focused on finding expressed customer needs. Likewise, a similar pattern is observed in the SC as we explored the school and office markets simultaneously. This is a synopsis of Blank's (2006) claim that products developed behind closed doors, with minimal early customer interaction almost always fail to find a place in the market.

As the team moved away from preconceived prototypes, the market orientation seemed to gradually manifest in light of the 'freedom' to pursue other market opportunities without the restriction posed by the consideration of specific set of features. The greatest implication of this finding is that the traditional product development paradigm, which is still profound in research institutions, is likely to favour the customer-led approach unless the product of the research can find a novel application in the market. Also known as the Linear Model of Innovation (Rothwell, 1994), this approach prioritises scientific research as the basis for innovation and plays down the role of the market and customers in the process. To establish and maintain market orientation, there must be a parallel process of customer development throughout the research process that ensures the consideration of market requirements.

Another interesting observation is the different developmental stages of the projects and the impact on market orientation. Our experience shows the level of product development imposes a degree of rigidity on the team's ability to study the market and discover opportunities. For instance, when a product had reached full development (i.e. Sound Concepts) without a clearly established customer need, becoming or maintaining market orientation proved a difficult task. The best we could do was to align what was already developed with an existing customer need to the extent that the concept/product features would allow product market fit. On the other end of the spectrum; HYV consisted of a validated set of market requirements and therefore market orientation was much more profound. NacreTech falls somewhere in between, as the core technology was still under 
development but there was initial prototype for proof-of-concept. In this instance the team invalidated the first proposed prototype as well as identifying a market opportunity for the core technology in the future.

\section{Innovator's entrepreneur's dilemma}

The search for an established customer need to some extent presented similar challenges to those faced by established firms serving both an existing customer need while also trying to innovate. Known as the innovator's dilemma (Christensen, 1997) these firms face the difficulty of diverting resources from sustaining innovation of existing technology that serves known customer needs, to the development of new gaps in the market in order to maintain industry leadership. The similarity is that we too faced the challenge of exploring existing markets while at the same time actively looking to find emerging customer needs. Limited resources meant the team could only focus on one objective at a time. After the first project, we realised that while it's valuable to look for an immediate and existing need at the start, there has to be a longer term vision somewhere in the midst of the market research if marketorientation is to be achieved. From the examples of NacreTech and Sound Concepts, it is evident that addressing present needs or expressed needs is likely to lead to another substitute to an existing solution. Therefore in order to build a successful advanced technology enterprise, we also realised the need for a longer term vision of identifying emerging customer needs that are more likely to breed novel innovation. 


\section{Conclusion: Lessons Learnt}

The purpose of this thesis was to investigate whether the LSM favours a customer-led or market-oriented approach to customer development. The 2013 MATE team's experience of following the LSM process was analysed in order to identify times when a particular approach might have been dominant, and the factors that contributed to it. The key lessons in the findings are summarised below. These lessons are also implications for teams that are using the LSM framework to learn about customers' needs.

The LSM process has been shown to support both customer-led and market-oriented approaches to discovering customer needs. When we approached customers with questions that are based on a solution hypothesis, the LSM process identified present needs. In contrast, leading the market validation with the problem hypothesis and allowing the market to dictate the core requirements of a solution is shown to support the discovery of latent customer needs.

When the customer-led approach was dominant, it is partly attributed to the existence of preconceived prototypes that were intended for a particular market. Furthermore, the degree to which we were customer-led as a result of pre-existing prototypes depended on the stage of development. Our experiences indicate that when a prototype has reached the final stages of development, it requires that the team searches for an existing market where there is a need for the features offered by the prototype. This approach is likely to lead to products with incremental improvements over existing products due to the primary focus on expressed customer needs. On the other hand, when the team worked on a technology that was in the early stages of development, there was a sense of freedom to explore potential gaps in the market. Once a novel opportunity had been identified, the team was then able influence the future development of the technology in order to make it commercially viable.

Our experiences show that domain knowledge is a vital piece in establishing and maintaining a market-oriented approach to understanding customer needs. Domain knowledge aids in navigating through market data in order to extract novel and meaningful insights. These insights help the entrepreneur make decisions like whether to pivot or persevere with a particular course of action. Domain knowledge also increases the likelihood of responding to market information in a proactive manner, through discovering and addressing latent customer needs. Establishing close relationships with emerging customers and lead users in a 
particular market can mitigate a degree of deficiency in domain knowledge. These subset groups of customers are visionaries in their industries, often facing future needs before mainstream customers. 


\section{Bibliography}

Adams, R. (2010). If you build it will they come? Three steps to test and validate any market opportunity. Hoboken, N.J.: Wiley.

Atuahene-Gima, K., Slater, S. F., \& Olson, E. M. (2005). The Contingent Value of Responsive and Proactive Market Orientations for New Product Program Performance. Journal of Product Innovation Management, 22(6), 464-482.

Baskerville, R., \& Lee, A. (1999). Distinctions Among Different Types of Generalizing in Information Systems Research. In Proceedings of the IFIP TC8 WG8.2 International Working Conference on New Information Technologies in Organizational Processes: Field Studies and Theoretical Reflections on the Future of Work.

Blank, S. (2006). The four steps to the epiphany: successful strategies for products that win (2nd ed.). Foster City, Calif.: Cafepress.com.

Callahan, J., \& Lasry, E. (2004). The importance of customer input in the development of very new products. $R \& D$ Management, 34(2), 107-120.

Cavana, R., Delahaye, B. L., \& Sekeran, U. (2001). Applied Business research: Qualitative and Quantitative Methods. John Wiley \& Sons Australia.

Christensen, C. (1997). The Innovator's Dilemma: When New Technologies Cause Great Firms to Fail. Boston: Harvard Business School Press.

Christensen, C. M., \& Bower, J. L. (1996). Customer power, Strategic Investment and the Failure of Leading Firms. Strategic Management Journal, 17(3), 197-218.

Ciccantelli, S., \& Magidson, J. (1993). Consumer Idealised Design: Involving Consumers in the Product Development Process. Journal of Product Innovation Management, 10(4), 341-347.

Creswell, J. W. (1998). Qualitative inquiry and research design: Choosing among five traditions. Thousand Oaks, California: Sage Publications. Thousand Oaks, California: SAGE Publications.

Day, G. S. (1994). The capabilities of market-driven organizations. Journal of Marketing, 58 (October), $37-52$.

Denzin, N. K., \& Lincoln, Y. S. (2003). Strategies of Qualitative Inquiry (Second edi., p. 460). Thousand Oaks, California: SAGE Publications.

Deshpande, R., Farley, J. U., \& Webster, F. E. (1992). Corporate Culture, Customer Orientation, and Innovativeness in Japanese Firms: A Quadrad Analysis - Marketing Science Institute. Marketing Science Institute (pp. 92-100). Cambridge, Massachusetts. 
Drucker, P. F. (1954). The Practice of Management (Reissue ed.). New York: HarperBusiness.

Eliashberg, J., Lilien, G. L., \& Rao, V. R. (1995). Minimizing Technological Oversights : A Marketing Research Perspective. In ISBM REPORT, Institute for the Study of Business Markets; Pennsylvania State University (Vol. 3004).

Furr, N., \& Ahlstrom, P. (2011). Nail it then scale it: the entrepreneur's guide to creating and managing breakthrough innovation. S.1.: NISI Institute].

Hamel, G., \& Prahalad, C. K. (1994). Competing for the Future. Boston, MA: Harvard Business Review Press.

Hippel, E. Von. (1986). Lead Users: A Source of Novel Product Concepts. Management Science, 32(7), 791-805.

Hippel, E. Von, Thomke, S., \& Sonnack, M. (1999). Creating Breakthroughs at 3M Job Sculpting: The Art of Retaining Your Best People A New Way to Manage Process Knowledge. Harvard Business Review, (September-October).

Hooley, G. J., \& Lynch, J. E. (1985). Marketing lessons from the UK's high-flying companies. Journal of Marketing Management, 1(1-2), 65-74.

Jaworski, B. J., \& Kohli, A. K. (1996). Market Orientation: Review , Refinement , and Roadmap. Journal of Market Focused Management, 35(1), 119-135.

Jaworski, B., Kohli, A. K., \& Sahay, A. (2000). Market-Driven Versus Driving Markets. Journal of the Academy of Marketing Science, 28(1), 45-54.

Kohli, A. K., \& Jaworski, B. J. (1990). Market Orientation: The Construct, Research Propositions and Managerial Implications. Journal of Marketing, 54(2), 1-8.

Lukas, B. A., \& Ferrell, O. C. (2000). The Effect of Market Orientation on Product Innovation. Journal of the Academy of Marketing Science, 28(2), 239-247.

Martin, J. (1995). Ignore Your Customer. Fortune Magazine. Retrieved from http://money.cnn.com/magazines/fortune/fortune_archive/1995/05/01/202476/

McNiff, J., \& Whitehead, J. (2002). Action Research in Organisations (p. 352). London: RoutledgeFalmer.

Miles, M. B., Huberman, A. M., \& Saldaña, J. (1994). Qualitative Data Analysis (2nd Edition.). Thousand Oaks, California: SAGE Publications.

Narver, J. C., \& Slater, S. F. (1990). The Effect of a Market Orientation on Business Profitability. Journal of Marketing, October, 20-35.

Narver, J. C., Slater, S. F., \& Maclachlan, D. L. (2004). Responsive and Proactive Market Orientation and New-Product Success. Journal of Product Innovation Management, 21(1990), 334-347. 
Neale, M., \& Corkindale, D. (1998). Co-developing Products: Involving Customers Earlier and More Deeply. Long Range Planning, 31(3), 418-425.

O'Leary, Z. (2004). The Essential Guide to Doing Research (p. 226). London: SAGE Publications.

Pelham, A. M., \& Wilson, D. T. (1995). A Longitudinal Study of the Impact of Market Structure, Firm Structure, Strategy, and Market Orientation Culture on Dimensions of Small-Firm Performance. Journal of the Academy of Marketing Science, 24(1), 27-43.

Pitt, L., Caruana, A., \& Berthon, P. R. (1996). Market orientation and business performance: some European evidence. International Marketing Review, 13(1), 5-18.

Reason, P., \& Bradbury, H. (Eds.). (2001). Handbook of action research: Participative inquiry and practice. London: SAGE Publications.

Ries, E. (2011). The lean startup: how today's entrepreneurs use continuous innovation to create radically successful businesses. New York: Crown Business.

Rothwell, R. (1994). Towards the Fifth-generation Innovation Process. International Marketing Review, 11(1), 7-31.

Salkind, N. (2010). Encyclopedia of Research Design (Vol. 1, p. 1776). Thousand Oaks, California: SAGE Publications.

Shapiro, B. P. (1988). What the Hell Is "Market Oriented"? Harvard Business Review, (November).

Silverman, D. (2006). Interpreting Qualitative Data: Methods for Analyzing Talk, Text and Interaction (3rd Editio., p. 448). London: SAGE Publications.

Slater, S. F., \& Mohr, J. J. (2006). Successful Development and Commercialization of Technological Innovation: Insights Based on Strategy Type. Journal of Product Innovation Management, 23(1), 26-33.

Slater, S. F., \& Narver, J. C. (1998). Customer-led and Market-oriented: Let's Not Confuse the Two. Strategic Management Journal, 19(January 1997), 1001-1006.

Tabrizi, B., \& Walleigh, R. (1997). Defining next-generation products: an inside look. Harvard Business Review, 75(6), 116-24.

Webster, F. E. (1988). Rediscovering the Marketing Concept - Marketing Science Institute (pp. 88-100). Cambridge, Massachusetts. 
9. Appendix 1 